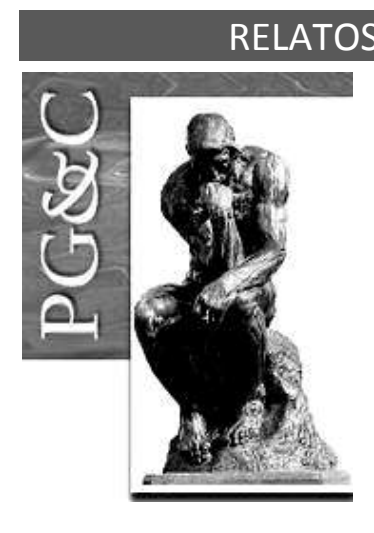

\title{
ONTOLOGIA COMO UM ARTEFATO DA ARQUITETURA DA INFORMAÇÃO PARA A REPRESENTAÇÃO DO CONHECIMENTO ORGANIZACIONAL
}

\author{
Sônia de Carvalho Palhares Beira \\ Mestre em Gestão do Conhecimento e Tecnologia da Informação pela \\ Universidade Católica de Brasília, Brasil. Coordenadora de projetos de TI da \\ Caixa Econômica Federal, Brasil. \\ E-mail: soniabeira@gmail.com \\ André Henrique de Siqueira \\ Doutor em Ciência da Informação pela Universidade de Brasília, Brasil. \\ Pesquisador associado ao Centro de Pesquisa em Arquitetura da \\ Informação, Brasil. \\ E-mail: andrehsiqueira@unb.br \\ Edilson Ferneda \\ Doutor em Ciência da Computação pelo Laboratoire d'Informatique, \\ Robotique et Microeléctronique de Montpellier, França. Professor da \\ Universidade Católica de Brasília. \\ E-mail: eferneda@pos.ucb.br

\section{Hércules Antonio do Prado} \\ Doutor em Ciência da Computação pela Universidade Federal do Rio \\ Grande do Sul, Brasil. Professor da Universidade Católica de Brasília, \\ Brasil. \\ E-mail: $\underline{\text { hercules@ucb.br }}$
}

\begin{abstract}
Resumo
Este trabalho teve por objetivo fundamentar teoricamente o processo de modelagem de informações organizacionais na forma de ontologias. Utilizaram-se as contribuições da Arquitetura da Informação, enquanto disciplina científica para a construção de ontologias organizacionais. É proposto um processo de elaboração de ontologias, cuja principal vantagem é prover um conjunto de diretrizes para a construção de ontologias, com propriedades de um construto científico, incluindo completude ao artefato, no que tange às características desejáveis. Serviu-se do Método de Arquitetura da Informação Aplicada (MAIA) para a condução do processo de construção de ontologias. Um estudo de caso foi desenvolvido no domínio financeiro. O principal resultado foi o mapeamento das contribuições do CPAI em recomendações de uso para a construção de ontologias de domínio.
\end{abstract}

Palavras-chave: Ontologia. Arquitetura da Informação. Gestão do Conhecimento. Tecnologia da Informação

\section{ONTOLOGY AS AN ARTIFACT OF INFORMATION ARCHITECTURE FOR THE REPRESENTATION OF ORGANIZATIONAL KNOWLEDGE}

\begin{abstract}
This work aimed at establishing a theoretical base for modelling organizational information in the form of ontologies. It was used the contributions of the Information Architecture as a scientific discipline for the construction of organizational ontologies. It is proposed a process of elaboration of ontologies. The
\end{abstract}

Perspectivas em Gestão \& Conhecimento, João Pessoa, v. 7, n. 2, p. 122-159, jul./dez. 2017. DOI: http://dx.doi.org/10.21714/2236-417X2017v7n2p122

http://periodicos.ufpb.br/ojs2/index.php/pgc. ISSN: 2236-417X. Publicação sob Licença (cc) EY-NC-ND 
advantage of this approach is to provide a set of guidelines for constructing ontologies, assuring properties of a scientific construct, including completeness to the artifact, with respect to the desirable characteristics. The Method of Information Architecture Applied (MAIA) was applied as guide to the process of construction of ontologies. A case study was developed in the financial field. The main result was the mapping of the CPAI contributions in recommendations for constructing domain ontologies.

Keywords: Ontology. Information Architecture. Knowledge Management. Information Technology.

\section{INTRODUÇÃO}

Zeleny (1980) indica a existência de quatro níveis para a Gestão de Conhecimento (GC): dados, informação, conhecimento e sabedoria. Dados representam a camada inicial, composta por símbolos ou sinais com característica puramente sintática e isentos de qualquer significado do ponto de vista da representação do conhecimento. As informações passam a ter um significado para a organização, onde o foco está no relacionamento entre os componentes do contexto e a finalidade destes componentes dentro do contexto. No nível de conhecimento, os relacionamentos entre os componentes e sua finalidade dentro do contexto são devidamente documentados e o seu propósito é divulgado para todos os relacionados dentro do contexto. De posse das informações levantadas, documentadas e internalizadas, a organização alcança o nível da sabedoria, podendo monitorar passo a passo o comportamento dos fenômenos e prever a ocorrência de problemas. Tal modelo tem sido utilizado como referencial para algumas iniciativas de GC.

Todavia, importantes questões podem ser colocadas com relação a este modelo: Qual o fundamento epistemológico para esta divisão? Que conceitos epistemológicos - uma teoria própria do conhecimento - podem ser tomados para uma correta apreciação das práticas de GC nas organizações? Identificar uma fundamentação teórica para esta separação implica em assumir pressupostos filosóficos e científicos com consequências tecnológicas.

As respostas a estes questionamentos tornam-se mais importantes quando se observa a relevância da GC para a sociedade atual. É notável o aumento da complexidade no tratamento da informação na sociedade moderna (MORIN, 1999). E a questão de identificar um referencial teórico adequado para o tratamento de tal complexidade exige uma fundamentação formal adequada.

Este trabalho se propõe a estabelecer uma relação entre o uso de ontologias de domínio como prática de GC e os fundamentos epistemológicos propostos para a disciplina da arquitetura da Informação (Al).

A Al é uma disciplina que tem por objetivo "a investigação do Mundo considerando as suas manifestações, formas, contextos e significados do ponto de vista de um Sujeito" (SIQUEIRA, 2012, p. 208). Segundo o autor, em sua caracterização e fundamentação da disciplina de Al, o problema crucial é o de perceber, pensar, desenhar e habitar Espaços de Informação. Isto decorre de uma reflexão detalhada sobre os fundamentos filosóficos, científicos e tecnológicos para a construção da disciplina. Esta abordagem, que se diferencia de outros tratamentos da $\mathrm{Al}$, oferece uma fundamentação teórica para a caracterização desta como disciplina científica.

Uma investigação sobre as práticas da Al situam-na como decorrente de um labor artesanal de organização e acesso à informação (ROSENFELD; MORVILLE, 2002; DADEROBERTSON, 2011). Ross, Weill e Robertson (2006) enfatizam a necessidade de uma Arquitetura Empresarial Estratégica por meio do uso de modelos de gestão de organização denominados blueprints. A mesma proposta é encontrada em Zachman (1987) quando este apresenta trinta e seis modelos em uma matriz de seis aspectos de negócio contra seis perspectivas de abrangência da Arquitetura Empresarial da Informação (Enterprise Information

Perspectivas em Gestão \& Conhecimento, João Pessoa, v. 7, n. 2, p. 122-159, jul./dez. 2017. 


\section{Architecture).}

A criação de uma ontologia é um processo cuja essência é caracterizada pelo conjunto de escolhas que permitem definir conceitos para um domínio específico observado. A própria ontologia define-se como um grupo de especificações formais sobre quais semânticas devem ser recuperadas quando determinado signo ou símbolo é apresentado. 0 problema tem suas raízes na Filosofia, com a busca pela essência das coisas ou seres, e desdobra-se na linguística através dos esforços da onomasiologia e da semasiologia. Através do estudo da significação, cuja metodologia de análise parte das noções ou conceitos para determinar as formas linguísticas a eles correspondentes, a onomasiologia realiza, no campo da linguística, a determinação das representações adequadas para os conceitos. Por outro lado, a semasiologia caracteriza-se como estudo da significação cuja metodologia de análise parte das formas linguísticas para indicar as noções ou conceitos a elas correspondentes. Do ponto de vista linguístico, uma ontologia é resultado de um esforço onomasiológico, na medida em que a sua criação estuda as noções e conceitos existentes em um domínio e os caracteriza na forma de classes, subclasses, propriedades, atributos e instâncias.

A informação desempenha papel fundamental nas organizações modernas. O seu ciclo de tratamento na organização envolve elementos para a captura, representação, caracterização, significação, armazenamento, recuperação, comunicação, uso e descarte. 0 desenvolvimento da tecnologia da informação e comunicação tem sido decisivo na diferenciação organizacional e no processo de criação de valor para o negócio. Vocabulários controlados, taxonomias e ontologias vêm se incorporando cada vez mais nesse processo. Nesse contexto, o grupo de pesquisadores do Centro de Pesquisa em Arquitetura da Informação (CPAI) ${ }^{1}$, da Universidade de Brasília, propõe um modelo de Al que, como se verá adiante, permite uma análise dos aspectos filosóficos, científicos e tecnológicos relacionados ao uso de ontologias e suas implicações para a GC nas organizações. Este trabalho utiliza como principal referencial teórico os resultados do CPAl, com vistas a responder à seguinte pergunta: Quais as contribuições da Al para o uso da técnica de ontologia como instrumento de GC nas organizações?

Este trabalho apresenta uma fundamentação de ontologias como ferramentas de representação do conhecimento. Seu objetivo central é caracterizar uma ontologia como um instrumento da GC no âmbito organizacional, segundo um arcabouço teórico oriundo da Al, que será apresentado ao longo do trabalho.

Trata-se de uma pesquisa de natureza teórica e analítica, que busca identificar um conjunto de diretrizes para a construção de ontologias em áreas específicas (ontologias de domínio), de acordo com uma fundamentação epistemológica. Para isto, utiliza-se uma visão de mundo que integra conceitos filosóficos, científicos e tecnológicos como partes de um corpo de conhecimento que se desenvolve a partir de uma abordagem fenomenológica e propõe uma epistemologia que considera o Sujeito e o Objeto do Conhecimento dentro de uma relação recíproca - o Sujeito determina o Objeto e é por ele determinado na construção do Conhecimento.

Parte-se de uma revisão de literatura sobre temas relacionados à $\mathrm{GC}$, aos diferentes conceitos de Al, a uma metodologia para construção de Arquiteturas da Informação e a ontologias para se elaborar um referencial de construção de ontologias específicas, resultantes da aplicação do conceito filosófico da Ontologia (estudo dos entes e de sua natureza) em domínios de conhecimento específicos com base nos conceitos teóricos e práticos decorrentes do referencial teórico utilizado. A partir desta revisão, destacam-se as contribuições da Al para a construção de ontologias de domínio e os fatores críticos de sucesso para o uso de ontologias de domínio na GC.

\footnotetext{
${ }^{1}$ http://cpai.unb.br
} 
O uso de ontologias tem sido efetivo em diferentes aplicações para representação do conhecimento em diversos domínios das organizações. Este fato decorreu da evolução da Inteligência Artificial em seus esforços para classificação do conhecimento iniciados com a prática de vocabulários controlados. Ontologias relativas a determinados contextos organizacionais podem ser compartilhadas, independentemente da aplicação, podendo, assim, serem utilizadas por diversos sistemas.

Uma ontologia pode ser definida como uma especificação formal e explícita de uma conceitualização compartilhada (GRUBER, 1995). Nessa definição, "formal" significa ser tratável por computadores; "explícita" diz respeito a conceitos, propriedades, relações, funções, restrições e axiomas claramente definidos; "compartilhado" quer dizer conhecimento consensual; e "conceitualização" refere-se a um modelo abstrato de algum fenômeno do mundo real.

Guizzardi (2007) considera que uma ontologia é um artefato computacional composto por um vocabulário de conceitos, suas definições e propriedades, um modelo gráfico que mostra as relações entre os conceitos e um conjunto de axiomas formais para restringir a interpretação dos conceitos e relações. Em outras palavras, uma ontologia define os termos, relacionamentos e demais elementos usados para descrever e representar uma temática formalizando o conhecimento do domínio e o que pode ser interpretado sobre o mesmo.

O uso de ontologias como prática de gestão possibilita a conversão de conhecimentos das pessoas em formas de representações institucionais, promovendo tanto o registro quanto a disseminação de conceitos dentro das organizações. O desafio de integrar duas disciplinas distintas - GC e Al - não se dá por motivos de interesse puramente acadêmico, mas principalmente pela importância que ambas desempenham na estruturação das organizações modernas e nos potenciais de contribuição para a construção de ontologias de domínio como formas de representação do conhecimento organizacional.

$\mathrm{Na}$ GC, o conhecimento é considerado um ativo organizacional, cuja representação e uso estão entre os elementos que podem garantir a geração de riqueza. Este trabalho propõe mecanismos que garantem a construção de ontologias segundo um viés epistemológico. $O$ resultado esperado é a caracterização dos potenciais de uso dos construtos teóricos da Al em iniciativas de GC utilizando ontologias de domínio como formas de representação do conhecimento organizacional.

No desenvolvimento deste estudo, foram realizadas: (i) a caracterização da Arquitetura da Informação como disciplina científica, (ii) uma análise dos fundamentos das ontologias como forma de representação do conhecimento, (iii) a caracterização da aplicação da ontologia de domínio para GC nas Organizações e Analisar e (iv) indicadas as contribuições da Al para a construção de ontologias de domínio.

\section{REFERENCIAL TEÓRICO}

Este capítulo apresenta uma revisão de literatura tomada como referência teórica para o tema desenvolvido. Inicia-se com uma visão geral da GC. É, então, discutido o conceito de Al sob a perspectiva tradicional e sob o enfoque do CPAI. Uma análise sobre Ontologias como instrumento de uma arquitetura da informação organizacional.

\subsection{Gestão do conhecimento}

Cianconi (2003) compreende que a GC, no ambiente corporativo:

[...] vem sendo considerada a solução (muitas vezes a panaceia) para os problemas organizacionais e inúmeras propostas para melhor codificá-la

Perspectivas em Gestão \& Conhecimento, João Pessoa, v. 7, n. 2, p. 122-159, jul./dez. 2017. 
utilizando recursos tecnológicos disponíveis vem sendo realizadas (CIANCONI, 2003, p. 20).

Logan (2006), contrapondo-se à conceituação que GC se refere à "criação, captura, organização, acesso e uso do conhecimento" (SPEK; SPIJKERVET, 1995; HARRIS et al. 1999), afirma:

Acreditamos, no entanto, que a GC não existe sem a colaboração, o que definimos como "o coração do modelo de processo GC". Acreditamos também que a GC não é uma classe separada da tecnologia. Em vez disso, usa muitas categorias de tecnologia, quase nenhuma das quais são exclusivas para GC. Por exemplo, a partilha de conhecimento faz uso de tecnologias de gerenciamento de conteúdo para realizar os processos de GC de captura, organização e acesso ao conhecimento (LOGAN, 2006, p. 2).

A autora empreende uma vasta revisão do material produzido sobre o tema e ressalta a necessidade de segmentação dos diferentes autores, e suas contribuições, dentro de uma proposta de estruturação considerando três focos distintos: (i) o foco contextual (ambiente social, cultural e econômico); (ii) o foco estrutural (as organizações e a evolução da teoria organizacional) e (iii) o foco conjuntural (aspectos teóricos e práticos da Gestão da Informação e do Conhecimento). O Quadro 1 resume o comparativo efetuado.

Quadro 1 - Síntese das abordagens de pesquisa em Gestão do Conhecimento

\begin{tabular}{|c|c|c|c|}
\hline Abordagem & $\begin{array}{l}\text { Instrumentos } \\
\text { metodológicos }\end{array}$ & Conceitos envolvidos & Principais autores \\
\hline $\begin{array}{l}\text { Contextual } \\
\text { (ambiente social, } \\
\text { cultural, } \\
\text { econômico) }\end{array}$ & $\begin{array}{l}\text { Inserção da } \\
\text { problemática na } \\
\text { sociedade atual }\end{array}$ & $\begin{array}{l}\text { - Sociedade da informação } \\
\text { - Globalização }\end{array}$ & $\begin{array}{l}\text { Bell, Castells, De Mais, } \\
\text { Lévy, Masuda, Minc, } \\
\text { Nora, Santos, } \\
\text { Schement, Toffler, } \\
\text { Wainwright }\end{array}$ \\
\hline $\begin{array}{l}\text { Estrutural } \\
\text { (a evolução da } \\
\text { teoria das } \\
\text { organizações) }\end{array}$ & $\begin{array}{l}\text { Análise da teoria das } \\
\text { organizações, das } \\
\text { características das } \\
\text { empresas e as } \\
\text { mudanças na } \\
\text { atualidade }\end{array}$ & $\begin{array}{l}\text { - Burocracia } \\
\text { - Organização } \\
\text { - Cultura organizacional } \\
\text { - Gestão } \\
\text { - Organizações do } \\
\text { conhecimento } \\
\end{array}$ & $\begin{array}{l}\text { Aldrich, Castels, De } \\
\text { Mais, Drucker, } \\
\text { Gurteen, Hassard, } \\
\text { Lafaye, Porter, Weber }\end{array}$ \\
\hline $\begin{array}{l}\text { Conjuntural } \\
\text { (a informação e o } \\
\text { conhecimento } \\
\text { nas organizações) }\end{array}$ & $\begin{array}{l}\text { Análise da gestão da } \\
\text { informação e do } \\
\text { conhecimento nas } \\
\text { organizações }\end{array}$ & $\begin{array}{l}\text { - Informação } \\
\text { - Conhecimento } \\
\text { - Gestão da informação } \\
\text { - Gestão do conhecimento } \\
\text { - Capital intelectual } \\
\text { - Inteligência organizacional } \\
\text { - Aprendizagem } \\
\text { organizacional }\end{array}$ & $\begin{array}{l}\text { Cronin, Devenport, } \\
\text { Edvinson, Malhotra, } \\
\text { Malone, McGee, } \\
\text { Nonaka, Prusak, Senge, } \\
\text { Stewart, Sveiby, } \\
\text { Takeushi, Terra, Wiig }\end{array}$ \\
\hline
\end{tabular}

Fonte: Cianconi (2003, p. 24)

A abordagem contextual estabelece as bases para o conceito de uma sociedade pósindustrial - uma economia de serviços baseada em conhecimento - que se contrapõe à sociedade industrial. O conceito pode ser identificado com bastante clareza em Drucker (1993). Preocupa-se em descrever a emergência do que vem sendo chamada de "a nova economia", aquela que surge com uma nova classe de trabalhadores composta de pesquisadores e tecnocratas cujo objeto de trabalho é a geração e uso de conhecimento desde a sua descoberta até a sua implementação em produtos da sociedade que reconfiguram 
processos e práticas historicamente construídas.

Autores como Porat, Bell, Drucker, Toffler e Castells vêm chamando a atenção para um deslocamento da economia em direção ao uso produtivo do conhecimento (CIANCONI, 2003). Para eles, a transformação do valor da mão-de-obra em trabalhadores do conhecimento virá a produzir profundas mudanças na sociedade como um todo e especialmente na economia. Esta autora identifica o surgimento, na literatura revisada, de duas grandes vertentes de atividades: as atividades de produção de conhecimento e as atividades de produção da informação. Entretanto, a caracterização da diferença entre os dois conceitos não é explicitada.

A abordagem estrutural analisa as questões da teoria das organizações e as características relacionadas ao impacto do conhecimento nas estratégias corporativas, na aprendizagem organizacional e nas mudanças que trazem para o marketing e comércio eletrônicos. Novamente, o trabalho de Drucker (1993) aparece como fundamental para esta abordagem, uma vez que este autor aponta o impacto que o trabalho do conhecimento trouxe para a definição da organização como uma instituição social moderna centrada em sua estrutura e função. Drucker destaca o papel que o conhecimento desempenha na composição da estrutura organizacional e como a modifica à medida em que se transforma em instrumento de reconfiguração dos conceitos sociais.

Castells (1999) destaca nesta abordagem o impacto do conhecimento no ambiente organizacional ao mostrar que a automatização - fruto direto da aplicação do conhecimento aos meios produtivos - tanto reduziu custos quanto aumentou a produtividade organizacional, levando os empreendedores a considerar a importância da GC, em particular o papel da inovação, como instrumento de competitividade empresarial.

Cianconi (2003) destaca ainda as contribuições de Domenico de Masi e Michael Porter nesta abordagem estrutural da GC, tanto pela análise do papel da criatividade (MASI, 2003) como pelo reconhecimento do papel crítico do conhecimento na construção das estratégias competitivas e na sua viabilização (PORTER, 1996).

A abordagem conjuntural caracteriza-se pelo estudo da evolução do papel da informação na sociedade e em sua evolução para modelos de Gestão da Informação e depois para a GC. Assim como Davenport, McGee e Prusak enfatizam a importância da separação entre tecnologia da informação e a informação propriamente dita. Estes autores ressaltam que a informação desempenha um papel mais importante do que a tecnologia em si e, portanto, precisa de políticas e estratégias específicas em seu tratamento.

Um aspecto importante na literatura de abordagem conjuntural é o retorno do conceito de Documento, agora tratado como unidade de informação organizacional.

Cianconi (2003) identifica o esforço de diferentes autores para uma caracterização adequada do que sejam os conceitos de Dado, Informação, Conhecimento e Sabedoria.

Caracterizar dado, informação, conhecimento e sabedoria pode não ser considerado relevante em alguns contextos, mas para os profissionais que têm na informação e no conhecimento o seu objeto de trabalho, é importante distingui-los, o mesmo ocorrendo para quem deseja entender as alterações no processo de geração e emprego do conhecimento para a inteligência competitiva das organizações. Dado-Informação-Conhecimento fazem parte de um processo de transmissão de conhecimento: dados (destituídos de significado e contexto), informação (o contexto no qual os dados podem ser inseridos, depende, entre outros do fator novidade, de assimilação) e conhecimento (conclusões, experiência acumulada). (CIANCONI, 2003, p. 29)

Cianconi (2003, p. 91) observa que muitos autores indicam que o termo "Gestão do Conhecimento" foi cunhado por Karl Wiig para a designação de sistemas especialistas para o 
tratamento de estruturas organizacionais que envolviam modelagem de processos e tomada de decisão utilizando Inteligência Artificial. Para Wiig, a GC envolve a coleção de processos que governam a criação, disseminação e promoção do conhecimento para realizar os objetivos da organização. Para Cianconi (2003) GC é:

[...] uma abordagem da empresa buscando pontos onde o conhecimento traga vantagem competitiva. Pode ser vista como um processo amplo de criação, uso e disseminação do conhecimento na empresa. A GC se traduz numa série de práticas facilitadoras do compartilhamento do conhecimento na empresa, tanto sobre seus processos internos quanto sobre seus clientes e seu ambiente competitivo. [...] o que vem sendo considerado como Gestão do Conhecimento é, sobretudo, uma tentativa de facilitar e criar melhores condições para a comunicação entre indivíduos, além de estimular, categorizar e formalizar as atividades de compartilhamento de experiências, a busca por codificar e explicitar o tácito, de promover o aprendizado permanente e continuado dos indivíduos nas organizações. (CIANCONI, 2003, p. 92)

A origem da distinção apontada por Cianconi (2003) foi identificada por Siqueira (2012) a partir dos trabalhos de Zeleny (1980). Adiante se verá como este autor critica a hierarquia Dado-Informação-Conhecimento-Sabedoria, visto por ele como um conceito vazio de fundamentação epistemológica.

Uma importante contribuição para a análise do conhecimento veio a partir do trabalho de Polanyi (1974), de onde decorre o tratamento do conhecimento como uma possibilidade corporativa. No texto, Polanyi desenvolve, entre outros, o conceito do conhecimento tácito. A ideia central de Polanyi sobre esse tipo de conhecimento é de que o homem é capaz de conhecer mais do que ele pode expressar. A representação codificada do conhecimento seria, então, sempre menor que o entendimento que o indivíduo faz do significado deste conhecimento.

Nonaka e Takeuchi (1995), baseando-se na obra de Polanyi, desenvolveram o modelo de aprendizado corporativo como requisito para a inovação, com seus impactos sobre a competitividade corporativa. Utilizando o conceito de conhecimento tácito, os autores distinguem o comportamento das empresas norte-americanas e japonesas. Segundo eles, as japonesas valorizam o conhecimento tácito - maior do que o entendimento que pode ser formalizado em codificações, enquanto as norte-americanas situavam seu interesse nos conhecimentos explícitos - aqueles que podem ser formalizados por meio de codificações formais. Baseando-se nos conceitos de Socialização, Externalização, Combinação e Internalização, os autores desenvolvem um modelo de aprendizado corporativo, pelo qual tentam explicar a transformação do conhecimento tácito em explícito. Outro conceito importante no trabalho de Nonaka e Takeuchi (1995) é o ba. Pode-se compreender esse conceito como os diferentes contextos de aprendizado - para os autores, um mecanismo estruturador do contexto específico no qual o conhecimento é utilizado, apreendido ou experimentado.

Encontramos uma crítica significativa ao modelo tradicional de GC, particularmente à visão tradicional de Nonaka e Takeuchi (1995), em Siqueira (2014, p. 7):

[...] os autores consideram que o conhecimento é sempre uma atividade dos seres humanos. É notável a concepção antropocêntrica adotada. Devido à assunção do modelo de aprendizado de Polanyi (1974), eiva-se o modelo de aprendizado corporativo de um ar de equívoco conceitual: as organizações não aprendem; somente os indivíduos são capazes de aprendizado. Organizações são acúmulos de conhecimentos de indivíduos. 
O modelo epistemológico, ontológico e temporal apresentado pretende falar sobre o aprendizado das organizações, mas detém-se no aprendizado dos indivíduos, que se projetam sobre as organizações. Não há fenômenos de aprendizado organizacional. Existem epifenômenos de aprendizado organizacional. Somente os indivíduos aprendem. As organizações padecem de ignorância estrutural. Embora apresentem mecanismos de explicação do aprendizado e infiram ações de otimização deste, os autores contrariam o fundamento teórico adotado: apresentam os entes passíveis de aprendizado (o indivíduo; o grupo; a organização e a inter-organização) e concluem ser o aprendizado um fenômeno exclusivo dos indivíduos.

Stewart (2001) defende que três grandes ideias marcaram o contexto da Administração no final do século XX: (i) o movimento da qualidade total; (ii) o movimento da reengenharia e; (iii) os conceitos de capital intelectual e de GC.

Para Stewart (2001), o conhecimento é um ativo que deve ser incluído como insumo fundamental na gestão dos negócios. Segundo ele (STEWART, 2001, p. 34), "em 1999, o conhecimento foi o principal item de exportação dos Estados Unidos - o país recebeu US\$37 bilhões em royalties e licenças". Este autor destaca o fato de que os ativos convencionais (físicos e financeiros) não desaparecerão ou diminuirão a sua importância no contexto organizacional, mas destaca que os ativos do conhecimento - tanto o capital intelectual quando os sistemas de GC - desempenharão um papel cada vez mais importante no cenário das organizações. Stewart destaca que o capital intelectual envolve talentos, habilidades, técnicas e relacionamentos que as pessoas dominam, além de incluir softwares e máquinas que incorporam conhecimento.

As organizações existem para cumprirem um papel social. Elas transformam recursos e conhecimentos em riquezas. As riquezas geradas pelas organizações podem ser de natureza financeira ou social, pois abrangem tanto a remuneração do capital quanto a execução de interesses sociais. É por isto que o problema central da GC é o uso do conhecimento como ativo organizacional, como instrumento de geração de riqueza.

Stewart (2001, p. 61-67) especifica que as empresas existem para realizar funções sociais. Elas se edificam em torno de um objetivo comum e devem atuar como um polo de atração de capital intelectual; como um polo de criação e cultura que permita a consecução do objetivo ao qual se propuseram. É neste ambiente cultural que se pode propiciar o desenvolvimento de ideias que alavanquem os objetivos da organização, possibilitando a cooperação entre todos os elementos reunidos (tanto físicos como humanos). É no contexto organizacional que se desenvolve o espaço adequado para a colaboração intelectual e física. Ao criar este ambiente, a empresa oferece as garantias necessárias para a execução de suas funções. Para este autor, é nas organizações que o conhecimento potencializa todo o seu valor, e o faz via cooperação entre os indivíduos alocados no trabalho intelectual.

Os ativos do conhecimento são desenvolvidos em torno das reais necessidades das organizações. É preciso definir bem os objetivos organizacionais para potencializar o capital intelectual e aplicar os ativos em prol dos objetivos aos quais se destina a organização. E este é o principal papel da GC: garantir que os ativos organizacionais, em particular o capital intelectual, gere valor para a organização.

Um aspecto importante na GC é que a relação entre investimento e retorno não é linear. Quando se dobra a quantidade de insumos numa linha de produção, pode-se dobrar a quantidade de produtos fabricados. Mas quando se dobra o investimento em Pesquisa e Desenvolvimento não é possível prever o resultado que isto irá gerar! Esta é uma das regras do capital intelectual (STEWART, 2001, p. 138).

A GC resulta para as organizações em três elementos (STEWART, 2001): (i) produtos do conhecimento; (ii) projetos do conhecimento e (iii) processos do conhecimento. 
Os produtos do conhecimento representam a aplicação do capital intelectual na incorporação de conhecimentos em resultados concretos. Um computador, um telefone móvel ou um assistente pessoal eletrônico são exemplos deste tipo de aplicação do conhecimento. Projetos do conhecimento dizem respeito ao uso de capital intelectual na criação de novos elementos. Neles o conhecimento é o elemento direcionador tanto do projeto quanto do produto que ele irá gerar. Facebook, WhatsUp e GoogleMaps são exemplos de projetos de conhecimento. Eles utilizam o conhecimento como insumo e como mecanismo de agregação de valor para os objetivos organizacionais. Os processos do conhecimento caracterizam-se pelo uso de capital intelectual para o desenvolvimento ou aprimoramento de rotinas ou atividades periódicas dentro da organização. Os processos de conhecimento resultam da aplicação do capital intelectual na criação de procedimentos de agregação de valor para as atividades da organização ou na produção de seus itens de negócio.

\subsection{Arquitetura da informação: abordagem tradicional}

A Al definida pelo Information Architecture Institute (2008, p. 1) como "a arte e ciência de organizar e rotular web sites, intranets, comunidades online e software, para suportar usabilidade", configura-se como uma importante ferramenta para organização de informações em diferentes suportes, a fim de facilitar o uso e acesso a estas. É utilizada ainda para dar forma a produtos e experiências de informação a fim de suportar usabilidade.

A expressão Arquitetura da Informação foi cunhada por Wurman (1997). Seu propósito era argumentar que a necessidade de configurar espaços para o habitar humano deveria ser estendida para os espaços digitais. 0 arquiteto da informação seria, então, o profissional responsável por aplicar uma metodologia de desenho a qualquer ambiente de informação. Wurman (1997) define que o arquiteto da informação é, ao mesmo tempo: (i) o individuo que organiza os padrões inerentes de dados tornando clara a complexidade e (ii) uma pessoa que cria a estrutura ou mapa da informação e que permite aos outros identificarem seus caminhos próprios para o conhecimento.

Davenport (1998) compreende que a Al, em um sentido amplo, é um conjunto de procedimentos para relacionar as necessidades de informação dos usuários com os recursos informacionais. Al seria um desenho arquitetural cuja organização estrutura as informações em formatos específicos, categorias, e relações dentro de uma organização.

Hagedorn (2000) estabeleceu o conceito de Al como "a arte e ciência da organização da informação para a satisfação de necessidades de informação, que envolve os processos de investigação, análise, desenho e implementação".

Haverty (2002, p. 839) destaca que a Al pode ser considerada um campo, mas que não havia alcançado o status de uma disciplina científica.

Para Dillon (2002), Al é um termo utilizado para descrever o processo de desenhar, implementar e avaliar os espaços de informação que são de interesse de determinados grupos sociais.

Rosenfeld e Morville (2002) estabeleceram as bases de uma arquitetura da informação como prática que busca: (i) o design estrutural de ambientes de informação compartilhada; (ii) a combinação de organização, rotulagem, pesquisa e sistemas de navegação em sites e intranets; (iii) a arte e a ciência de dar forma a produtos de informação e experiências para apoiar a usabilidade e encontrabilidade; (iv) a definição de uma disciplina emergente e uma comunidade de prática focada em trazer princípios do design e da arquitetura para a paisagem digital.

Bayle (2003) define Al como "a arte e a ciência de estruturar e organizar sistemas de informação com vistas a auxiliar as pessoas a atingirem seus objetivos".

Lamb (2004) define que a "Al é o processo de identificação, organização e controle da

Perspectivas em Gestão \& Conhecimento, João Pessoa, v. 7, n. 2, p. 122-159, jul./dez. 2017. 
informação para uma necessidade particular", processo este que envolveria aspectos tanto de arte quanto de ciência.

De uma maneira geral, observa-se o consenso de que Al é o resultado de uma prática de organização da informação para facilitar o acesso aos usuários. Nesta abordagem busca-se um conjunto de estratégias para acesso e disseminação de informações no âmbito das organizações. Compreende-se que a Al tem como objetivo criar instrumentos para oferecer conteúdos relevantes às pessoas certas e no tempo correto.

Em uma reflexão sobre os principais referenciais e teorias da Al, Lacerda (2005, p. 104) identifica os seguintes elementos:

- Usuários necessitam de informação certa no tempo certo;

- Sem a intervenção humana, a informação transforma-se em entropia e caos (postulado baseado na Teoria Geral dos Sistemas de Bertalanffy);

- É necessário trabalho especializado para estruturar informação;

- Com a Internet surgiu um ambiente de informação compartilhado, que mudou a forma como convivemos com a informação. Agora, os usuários esperam informações acessíveis e imediatas dos sistemas de informação;

- A quantidade de informações cresce exponencialmente (fenômeno da explosão informacional, para o qual a Ciência da Informação dedica seus estudos);

- A Arquitetura da Informação é interdisciplinar e tem diversos profissionais envolvidos em sua implementação. Aplica métodos e conceitos advindos da Ciência da Informação e de outras áreas, tais como vocabulários controlados, esquemas de classificação, modelos mentais, interação homem-máquina, etc.;

- A Arquitetura da Informação é: primeiro, um processo, segundo, uma prática (profissão) e, por fim, uma disciplina. A prática fortalece a disciplina e promove seu desenvolvimento;

- São objetivos da Arquitetura da Informação: desenvolver ambientes informacionais semanticamente relevantes; modelar informação em ambientes que possibilitem sua criação, gestão e compartilhamento pelos usuários; e promover a melhoria da comunicação, da colaboração e do intercâmbio de experiências;

- Informações só existem em contextos específicos, para 'comunidades de significado', caso contrário, são dados;

- Pessoas em primeiro lugar, tecnologia em segundo (visão humanista);

Rosenfeld e Morville (2002) analisam os benefícios da Al para as organizações, destacando como fatores críticos na prática da Al: (i) o custo de encontrar informações, (ii) o custo de não encontrar informações; (iii) o custo de uso das informações; (iv) o custo de desenvolvimento e gestão de sistemas de informação; $(v)$ o valor de educar funcionários e clientes; (vi) o valor de criar redes de conhecimento; (vii) o valor de fortalecer a marca; e (viii) o valor de promover inovações. Eles identificam três categorias para a estruturação da Al, conforme apresentado na Figura 1: 
Figura 1 - Categorias para a Arquitetura da Informação

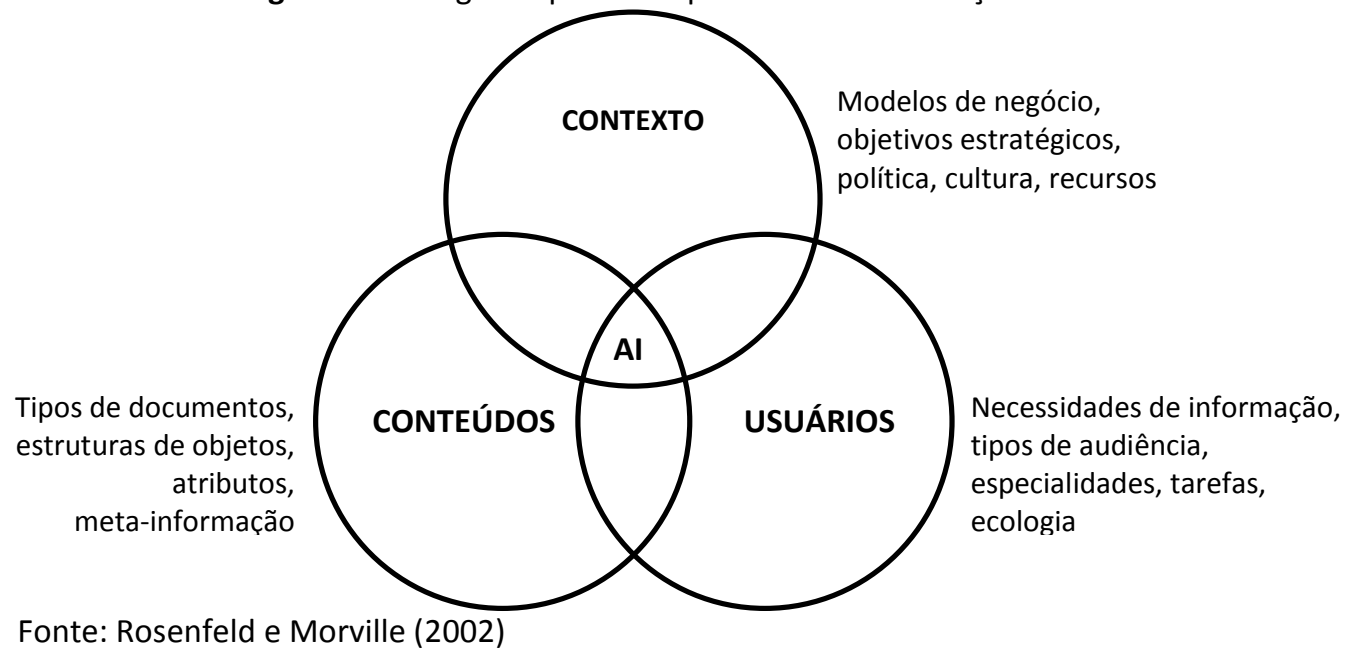

Lacerda (2005) comenta acerca do trabalho de Rosenfeld e Morville:

Partir da analogia com a arquitetura tradicional tem sido uma metodologia bastante eficaz para a compreensão da natureza complexa e multidimensional dos espaços informacionais, como observam Rosenfeld e Morville. Nesse sentido, os autores afirmam que, sendo conhecedores do ramo da arquitetura ou quaisquer indivíduos, estão todos "emocionalmente envolvidos pelas estruturas físicas que experimentam durante suas vidas". E citam Winston Churchill, ao declarar que "nós modelamos nossos edifícios: depois eles nos modelam". Desse modo, cada edifício cumpre seu papel de maneira única, sendo que todos os elementos - a arquitetura, o desenho, a construção, o mobiliário, os habitantes e a localização - funcionam em conjunto, de forma sistêmica, e cada um exerce um papel importante na modelagem da experiência como um todo (LACERDA, 2005, p. 113).

Reis (2007) apresenta, em sua revisão de literatura sobre a Al, um quadro de referência composto de cinco fases: Pesquisa, Concepção, Especificação, Implementação e Avaliação. Os princípios das abordagens de Design Centrado no Usuário são aplicados nas duas fases iniciais, sendo que na primeira é aplicada a abordagem da Ciência da Informação, e na segunda a abordagem da Interação Humano-Computador. Sobre a importância de centrar o usuário como fundamento da $\mathrm{Al}$, Reis $(2007$, p. 58) considera:

Tanto a abordagem de Design Centrado no Usuário da Interação HumanoComputador quanto da Ciência da Informação buscam conhecer e atender o usuário tendo-o no centro das decisões ao realizar o design de seus sistemas. Porém cada uma dessas abordagens possui princípios próprios, mas que se complementam.

A Interação Humano-Computador tem como foco compreender como o usuário executa suas tarefas ao interagir com as interfaces computacionais e por isso apresenta uma visão mais operacional, voltada principalmente ao uso do sistema. Através das suas avaliações de usabilidade, essa disciplina busca mapear as dificuldades dos usuários nas suas tarefas para tornar o uso das interfaces computacionais mais fácil e intuitivo.

A Ciência da Informação, de forma complementar, busca compreender toda a situação e o comportamento do usuário na sua busca de informação, antes, durante e depois da sua interação com o sistema. Por isso essa ciência apresenta uma visão mais holística do usuário, de suas necessidades 
e de como ele se relaciona com o mundo, fruto de um pensamento mais reflexivo.

Essas duas disciplinas podem trazer importantes contribuições para a Arquitetura de Informação, fornecendo técnicas e fundamentação teórica para a sua metodologia de projetos. A abordagem da Interação HumanoComputador pode contribuir com técnicas para identificar as tarefas dos usuários e avaliar seu uso do website. Já a abordagem de Design Centrado no Usuário da Ciência da Informação pode contribuir com técnicas para realizar pesquisas mais abrangente sobre os usuários e suas necessidades.

A principal característica das abordagens tradicionais em Al é que elas se mantêm vinculadas ao conceito de Arquiteto de Informação criado por Richard Wurman, como assinala Reis (2007):

\begin{abstract}
Apesar da sua evolução, a Arquitetura de Informação ainda segue a definição criada originalmente por Wurman: trata de organizar a informação para torná-la clara. Na Web, esse objetivo se mantém: criar as estruturas de organização da informação apresentada por um website para que o usuário consiga encontrar e compreender as informações que necessita e desempenhar suas tarefas com facilidade (REIS, 2007, p. 63).
\end{abstract}

Apesar de sua importância no campo das aplicações práticas, a Al se beneficiaria de uma apresentação sob um referencial teórico coerente, pelo fato de alcançar o nível de uma disciplina científica. Tal condição abre novas possibilidades para a sua aplicação, em face das propriedades que podem ser estabelecidas a partir de uma abordagem científica. Isto porque a prática artesanal da disciplina é incompatível com a criticidade de tratamento de informação requerido no momento contemporâneo. A busca de tal fundamentação caracteriza o programa de pesquisa do CPAI.

\title{
2.3 Arquitetura da informação: abordagem do CPAI
}

Nesta seção são apresentados o conjunto de contribuições do CPAl para a fundamentação científica da Al.

\subsubsection{As principais contribuições do CPAI}

O CPAI tem por propósito investigar os fundamentos, os métodos e as aplicações da Al nas mais diversas áreas do conhecimento. É adotada no Centro uma abordagem que contempla os fundamentos filosóficos (em particular os ligados à epistemologia), fundamentos científicos e implicações práticas (de natureza tecnológica) relacionados à Al.

A disciplina de Al foi definida pelo CPAl como:

[...] um esforço sistemático de identificação de padrões e criação de metodologias para a definição de espaços da informação, cujo propósito é a representação e manipulação de informações; bem como a criação de relacionamentos entre entidades linguísticas para a definição desses espaços da informação (SIQUEIRA, 2012, p. 124)

O CPAI destaca a importância de uma epistemologia para a abordagem do problema da informação. Neste sentido, propõe a adoção da fenomenologia como fundamento filosófico para a apresentação do problema (LIMA-MARQUES, 1992; MACEDO, 2005; MARCIANO, 2006; OLIVEIRA, 2006; SANTOS, 2006; SILVA, 2006; SUGANUMA, 2006; LORENS, 2007; NASCIMENTO, 2008; SIQUEIRA, 2008; CAVALCANTE, 2009; COSTA, 2009; ALBUQUERQUE, 2010; DUARTE,

Perspectivas em Gestão \& Conhecimento, João Pessoa, v. 7, n. 2, p. 122-159, jul./dez. 2017. 
2010; MELO, 2010; ARAÚJO, 2012; OLIVEIRA, 2012; SIQUEIRA, 2012).

As principais contribuições teóricas do CPAI para uma nova conceituação do que seja a Al são sintetizadas na Figura 2.

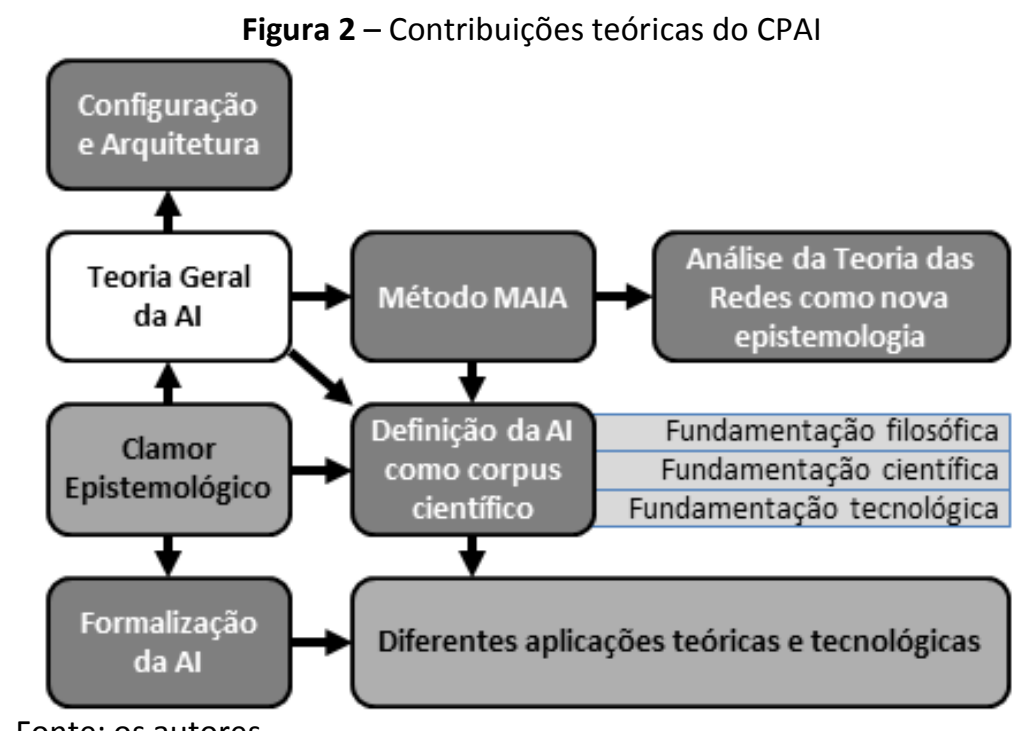

Fonte: os autores

O modelo fenomenológico proposto pode ser assim resumido:

- Mundo é a realidade observada. A informação é um ente da realidade que se manifesta através de fenômenos. Os fenômenos apresentam uma parte da realidade para o sujeito. A parte da realidade à qual o sujeito tem acesso é denominada dados.

- Conhecimento é a realidade representada. O conhecimento é o espelho da realidade segundo o entendimento do sujeito.

A informação é tomada como elemento básico da realidade. A partir da informação, da matéria e da energia, configuram-se fenômenos, os eventos da realidade percebida pelo sujeito. O sujeito tem acesso a apenas uma parte das informações da realidade: os dados. Os dados afetam as percepções do sujeito e lhe permite criar um entendimento da realidade, ou seja, o conhecimento.

\subsubsection{Necessidade de fundamentação teórica: clamor epistemológico para Al}

Um dos pontos mais importantes do trabalho do CPAl foi a identificação de uma necessidade de fundamentação epistemológica para a Al. Em Lacerda (2005) encontra-se uma análise do desenvolvimento de conceitos reunidos em torno da área de Al e o destaque para diferentes autores que clamam por uma fundamentação teórica para as práticas da disciplina. Em resposta ao clamor, a autora apresenta uma visão de mundo baseada na inter-relação entre Epistemologia, Ciência e Aplicações e propõe uma abordagem integrada que considere o Usuário, Contexto e Aplicação, como primeiros fundamentos da Al.

A identificação de ausências de fundamentação teórica nas práticas de Al até 2005 e a proposta de uma abordagem epistemológica científica e prática foi um marco para caracterizar a abordagem do CPAl.

\subsubsection{Lógica e Linguagem como fundamentos da Al}

Siqueira (2008) ofereceu uma resposta ao clamor identificado por Lacerda (2005), indicando que os fundamentos teóricos da Al estão baseados em modelos lógicos e linguísticos.

Perspectivas em Gestão \& Conhecimento, João Pessoa, v. 7, n. 2, p. 122-159, jul./dez. 2017. 
A argumentação é que a realidade é representada em modelos de Al. A linguagem funciona como mecanismo de representação de significados, e a lógica de instrumento para formalização da representação. Com esta abordagem o autor propõe um vocabulário técnico onde são identificadas palavras reservadas que compõem os principais conceitos da Al.

O autor caracteriza o problema central da Al como um problema filosófico de representação da realidade em termos de uma relação de elementos em um espaço de informação. Para esta representação deveriam ser utilizadas a linguagem e a lógica. Para ele, a informação passa a ser vista como um elemento básico na natureza, responsável pela organização dos sistemas naturais. Os sistemas humanos são representações lógico-linguísticas das percepções do Sujeito acerca dos sistemas naturais. Neste sentido funcionam como suposições da realidade. Os sistemas artificiais, por outro lado, são construções do sujeito em termos de Al e o seu propósito é organizar os espaços da informação para atender a objetivos específicos priorizados pelo Sujeito.

Em relação aos aspectos filosóficos da Al, mais especificamente os epistemológicos, Siqueira (2008) propõe que:

[...] a representação da informação para um sujeito é um problema filosófico central na disciplina de Arquitetura da Informação. A representação viabiliza a compreensão do objeto representado e implica numa interação hermenêutica entre o sujeito e o mundo representado. Assim, o problema da experiência e representação da realidade em modelos semióticos lógico-linguísticos é uma questão central na disciplina de Arquitetura da Informação (SIQUEIRA, 2008, p. 71).

A noção de que a construção de uma arquitetura da informação é baseada em processos de suposição fundamenta-se nos conceitos filosóficos nominalistas. A partir do conceito de suposição - um mecanismo de substituição de termos por equivalentes em contextos específicos -, Siqueira (2008) propõe dois conceitos fundamentais: (i) $A$ suposição fenomenológica - um processo de representação da realidade que é continuamente atualizado pela observação. O propósito da suposição fenomenológica é fazer o sujeito conhecer a realidade em seus mais adequados detalhes. Os detalhes são priorizados pela intenção do Sujeito. (ii) A suposição estrutural - um processo de representação em que a realidade é congelada em uma representação lógico-linguística dela: um modelo que atende às necessidades e propósitos do Sujeito interessado no Espaço da Informação modelado.

Para o uso adequado dos conceitos da $\mathrm{Al}$, o autor propõe um vocabulário técnico reservado, a partir do qual deriva as regras de uso da $\mathrm{Al}$.

\subsubsection{O Método de Arquitetura da Informação Aplicada}

A prática da Al, conforme identificado por Lacerda (2005), caracterizava-se como uma prática artesanal de configuração de elementos na Web. Os primeiros a disciplinarem um processo técnico para a produção de arquiteturas da informação foram Rosenfeld e Morville (2006), mas o processo possuía uma fundamentação epistemológica inadequada.

Costa (2009) desenvolve o Método de Arquitetura da Informação Aplicada (MAIA), cujas principais características permitem aplicar os conceitos filosóficos, científicos e práticos da visão do CPAI. Baseando-se no conceito fenomenológico da interação entre Sujeito e Objeto, o método propõe que a construção de uma arquitetura da informação exija a distinção de quatro momentos: Escutar, Pensar, Construir e Habitar. Nesse trabalho, o autor propõe a definição dos Atos de Transformação. Cada momento do método faz uso de conjuntos de Atos de Transformação específicos (Figura 3). Os atos centrais do método são: Ouvir, Interpretar, Modelar, Transformar e Estar.

Perspectivas em Gestão \& Conhecimento, João Pessoa, v. 7, n. 2, p. 122-159, jul./dez. 2017. 


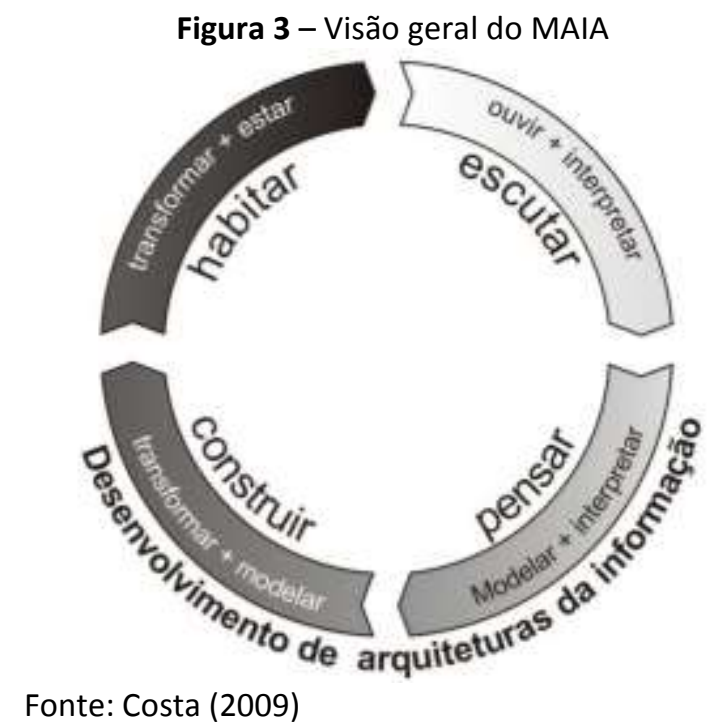

Com o desenvolvimento do MAIA, o CPAI propõe um roteiro de desenvolvimento de arquiteturas da informação, como objetos resultantes da prática da disciplina.

\subsubsection{Formalização Teórica da Al}

Prosseguindo com a resposta ao clamor epistemológico indicado por Lacerda (2005), Albuquerque (2010) apresenta uma formalização conceitual da disciplina de Al baseando-se em dois modelos centrais: Teoria das Categorias e Álgebra de Fronteiras. Esse trabalho trouxe a caracterização de três usos distintos da Al: (i) como disciplina; (ii) como objeto de investigação; e (iii) como resultado tecnológico. Há neste autor uma preocupação central de construir um modelo formal para a expressão dos conceitos da Al, contribuindo para o uso formal de uma linguagem própria da Al e caracterizando a própria disciplina em distinção com outras áreas do conhecimento.

\subsubsection{Teoria Geral da Arquitetura da Informação}

Um marco efetivo das contribuições do CPAl foi a publicação de Outline of a theoretical framework of Architecture of Information: a School of Brasilia proposal (LIMAMARQUES, 2011). Neste trabalho o autor apresenta os fundamentos teóricos da Al baseandose nos conceitos de Espaço de Informação, Configurações de informações em Espaços; Atos de Transformação e Intencionalidade nos Atos de Transformação.

A prática da Al começa pela delimitação de um Espaço qualquer (SIQUEIRA, 2012). A ideia de delimitação é a caracterização do espaço. Aos elementos existentes neste espaço é possível associar um espaço de informação que tem uma Disposição (arranjo ou disposição de alguma coisa) específica, uma Apresentação (maneira ou estilo no qual alguma coisa é dada ou mostrada) própria e uma Configuração (arranjo de elementos em uma forma, figura ou combinação particular). Estes elementos juntos constituem o Estar da Informação, conforme mostrado na Figura 4.

Um sujeito pode intencionalmente alterar os Estados no Espaço da Informação através de Atos de Transformação. Uma arquitetura da informação é uma configuração dos estados das coisas ou de suas representações. É através dos Atos de Transformação que um sujeito interfere no Espaço da Informação para criar uma arquitetura da informação que atenda aos seus interesses, conforme apresentado na Figura 5.

Qualquer mudança no Estar da Informação (Disposição, Apresentação ou 
Configuração) cria um novo Estado no Espaço da Informação. As mudanças no Estado ocorrem ao longo do tempo. A cada Estado é possível associar uma temporalidade $t$, como visto na Figura 6.

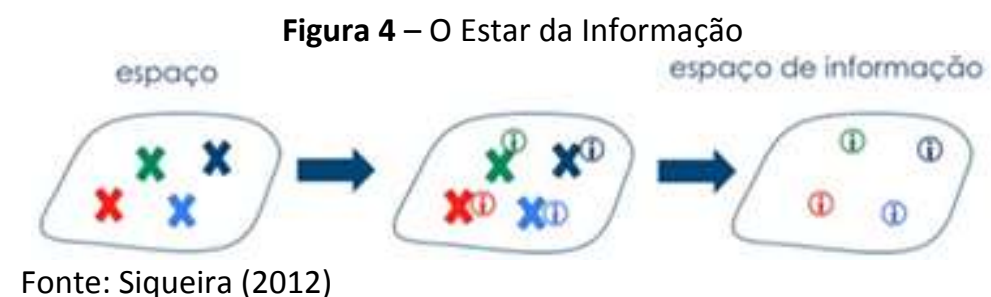

Fonte: Siqueira (2012)

Dinâmica:

Figura 5 - Estados no Espaço da Informação

$$
\mathcal{Q}_{\text {estados }}=\left\{\mathscr{E}_{t}, \mathscr{E}_{t}, \mathscr{E}_{t}, \ldots\right\}
$$

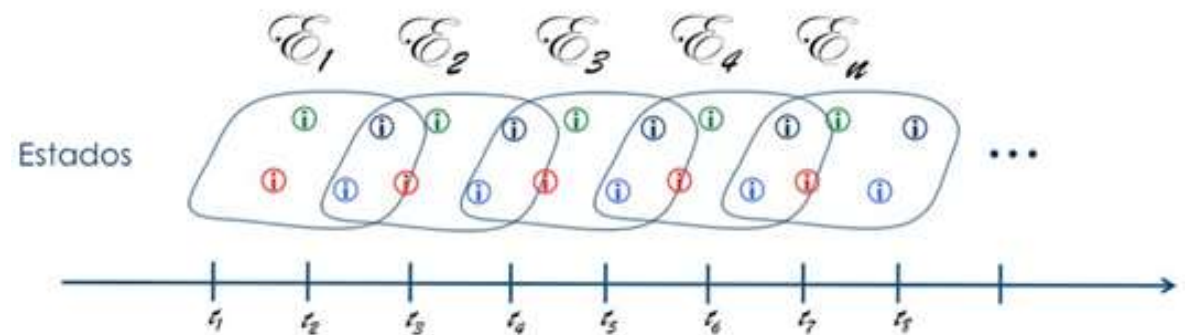

Fonte: Siqueira (2012)

Figura 6 - Atos de Transformação no Espaço da Informação

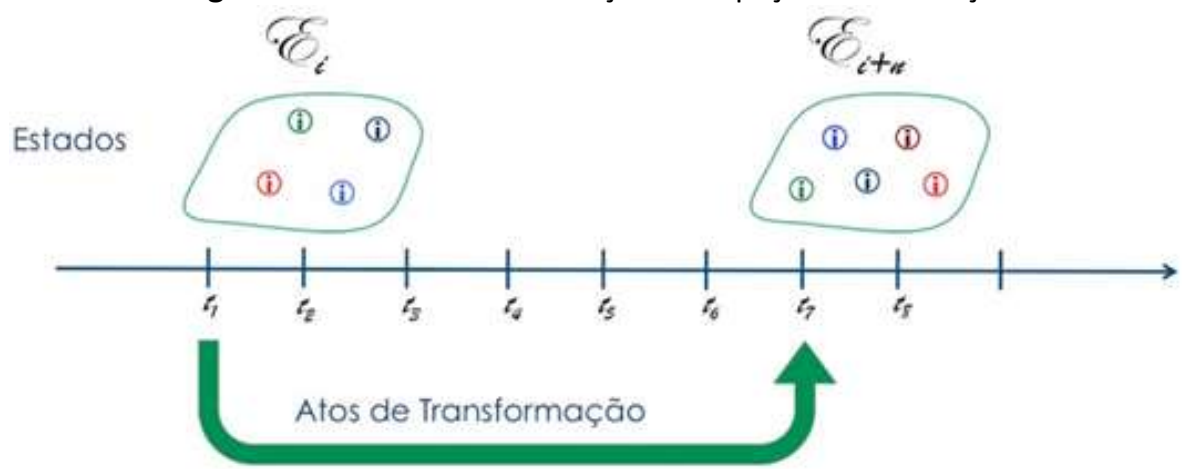

Fonte: Siqueira (2012)

\subsubsection{Distinção entre Configuração e Arquitetura da Informação}

Dentro do cenário da Teoria Geral da Arquitetura da Informação (LIMA-MARQUES, 2011), o CPAl percebeu que o conceito de Arquitetura somente poderia ser aplicado às intervenções dos Sujeitos nos Espaços de Informação. Tais intervenções se dão através dos Atos de Transformação realizados pelo Sujeito. Entretanto, as pesquisas mostraram que os Espaços de Informação são elementos naturais, estão presentes mesmo na ausência do Sujeito. Aplicar o conceito de Arquitetura a um Espaço de Informação que não está associado a qualquer sujeito criaria problemas na formalização teórica definida.

Para resolver o problema conceitual criado, Araújo (2012) propõe uma distinção entre Al e Configuração da Informação. Uma configuração é um arranjo espontâneo da informação

Perspectivas em Gestão \& Conhecimento, João Pessoa, v. 7, n. 2, p. 122-159, jul./dez. 2017. 
que se define por Estados do Espaço da Informação nos quais não há interferências de Sujeitos. Uma arquitetura da informação, por outro lado, é um Estado do Espaço da Informação que resultou de um ou mais Atos de Transformação originados por um Sujeito. A distinção entre Configuração da Informação e Al possibilitou uma delimitação mais clara da disciplina e de sua abrangência.

\subsubsection{Definição de Al como um corpus científico}

A partir dos construtos desenvolvidos pelo CPAl, Siqueira (2012) compilou uma proposta de fundamentação filosófica, científica e tecnológica para a Al como disciplina científica. $O$ autor enfatiza as seguintes proposições: (i) Os conceitos e práticas geralmente utilizados em Al mostram-se inadequados para caracterizá-la como uma disciplina científica. (ii) É possível construir um corpo de conhecimento para a Al que atenda aos critérios de uma disciplina científica. (iii) É possível caracterizar o campo de pesquisa que investiga os fenômenos da existência, estrutura e configuração da informação, suas diferentes transformações e seus usos em contextos multidisciplinares. Com tais premissas o autor desenvolve o seguinte argumento:

Se

I. Existe um critério de demarcação $C_{d}$ para determinar que um corpus de conhecimento $k$ seja uma disciplina científica.

II. A proposta do CPAI ( $\left.P_{C P A I}\right)$ é um corpus de conhecimento para a AI.

III. A proposta do CPAI $\left(P_{C P A I}\right)$ atende ao critério de demarcação $C_{d}$.

então

A proposta $P_{C P A I}$ é um corpus de conhecimento para a Al que determina uma disciplina científica.

Os desenvolvimentos advindos dos esforços na exploração deste argumento por Siqueira (2012) são:

- A caracterização dos fundamentos filosóficos da disciplina de Al. A Figura 7 representa os fundamentos da Ontologia, da Fenomenologia e da Epistemologia da Al. Como decorrência desta abordagem filosófica, Siqueira (2012) propõe uma alteração no conceito da hierarquia da informação, apresentado na Figura 8.

Figura 7 - Fundamentos filosóficos da Al

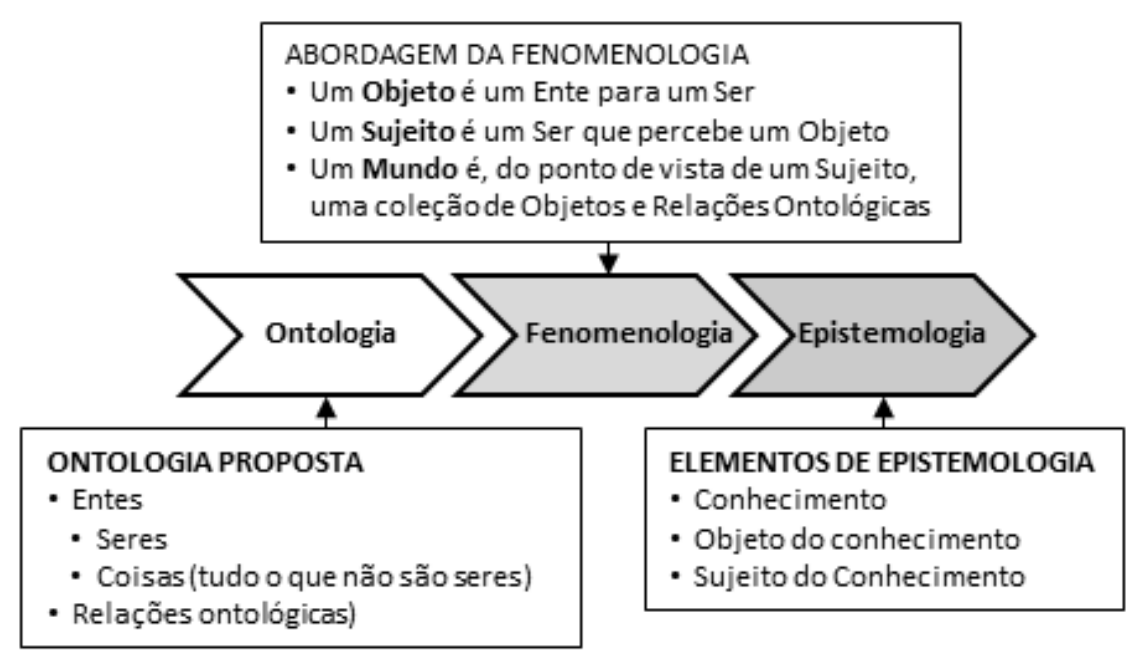

Fonte: Siqueira (2012) 
Figura 8 - Relação entre Informação, Dado e Conhecimento

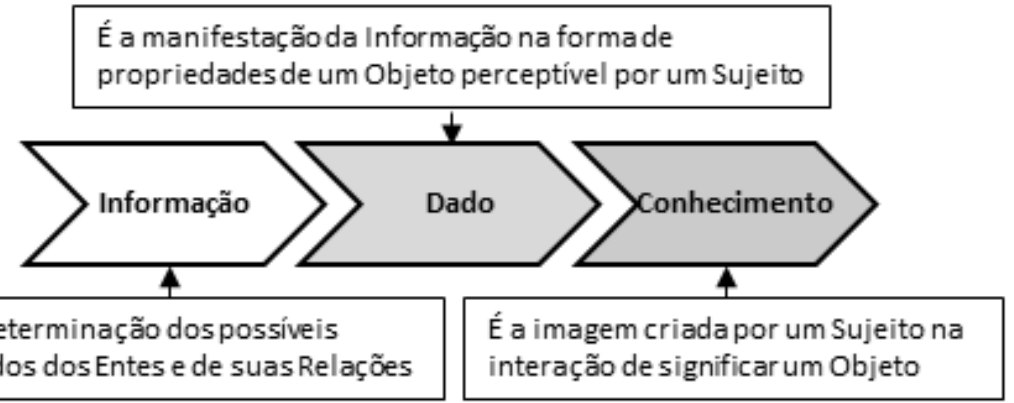

Fonte: Siqueira (2012)

- A definição da Teoria Geral da Al como esquema teórico para a Al. A introdução de quatro categorias fundamentais - Manifestação, Forma, Contexto e Significado - para a delimitação do domínio de estudos da Al, diferenciando-a de outras disciplinas (Figura 9).

- A apresentação dos Atos de Transformação fundamentais para disciplina Al (Figura 10).

- A definição dos princípios tecnológicos da Al (Figura 11).

- A proposta de um processo prático, baseado no MAIA, para a criação de artefatos tecnológicos utilizando-se os conceitos da Al é mostrada na Figura 12. A conceituação de AID e AIP, presentes na figura, é apresentada na seção 4.3.3.

Figura 9 - Categorias fundamentais da Al

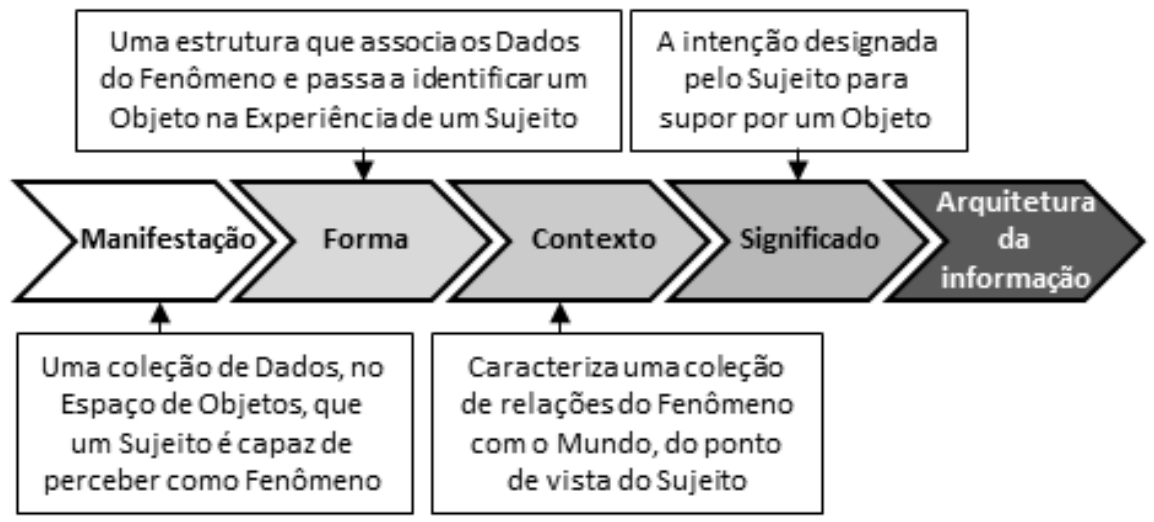

Fonte: Siqueira (2012)

Figura 10 - Atos de transformação fundamentais da Al

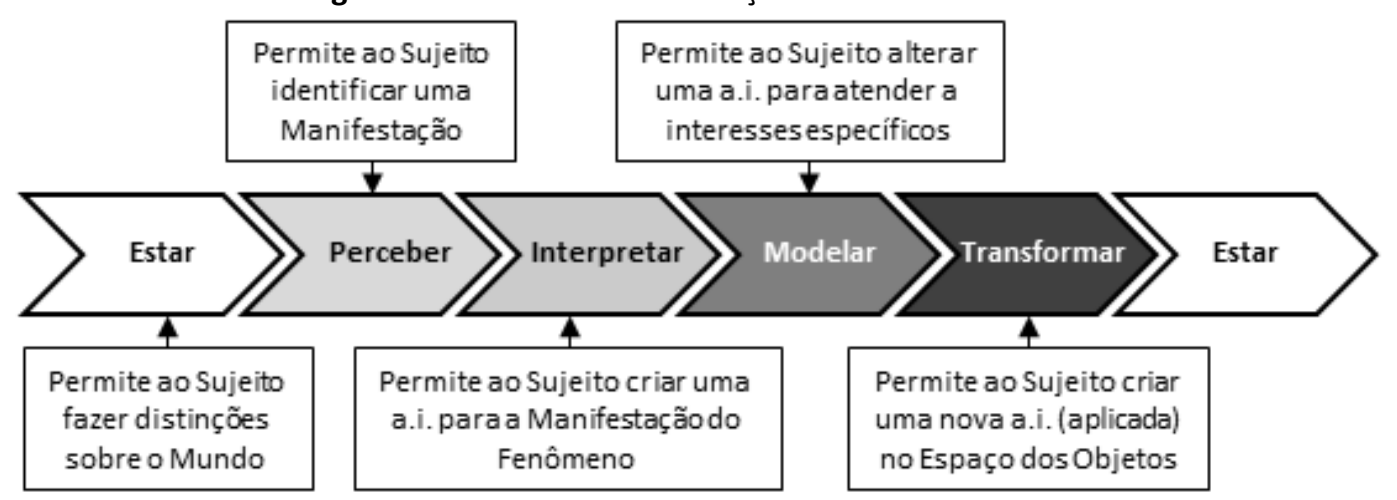

Fonte: Siqueira (2012) 
Figura 11 - Princípios tecnológicos utilizados na Al

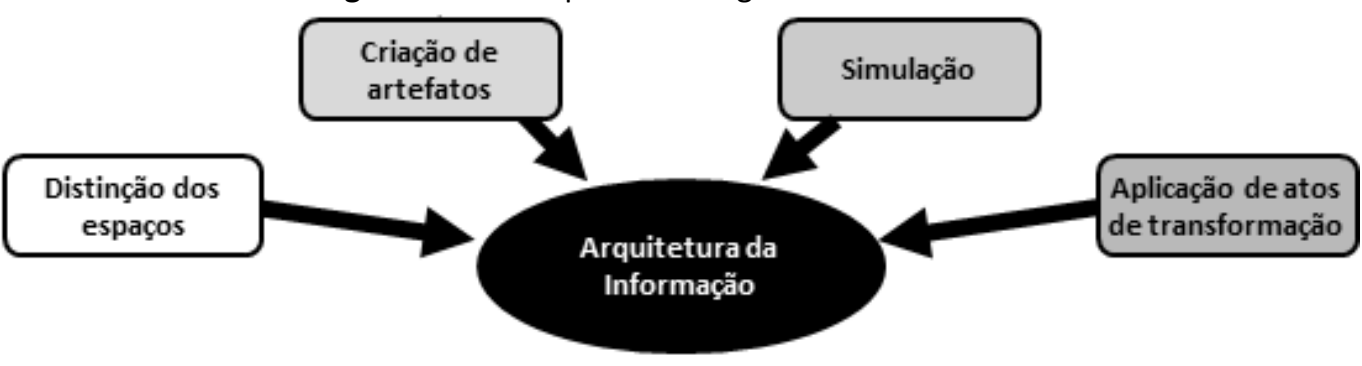

Fonte: Siqueira (2012)

Figura 12 - Processo prático para criação de artefatos na Al

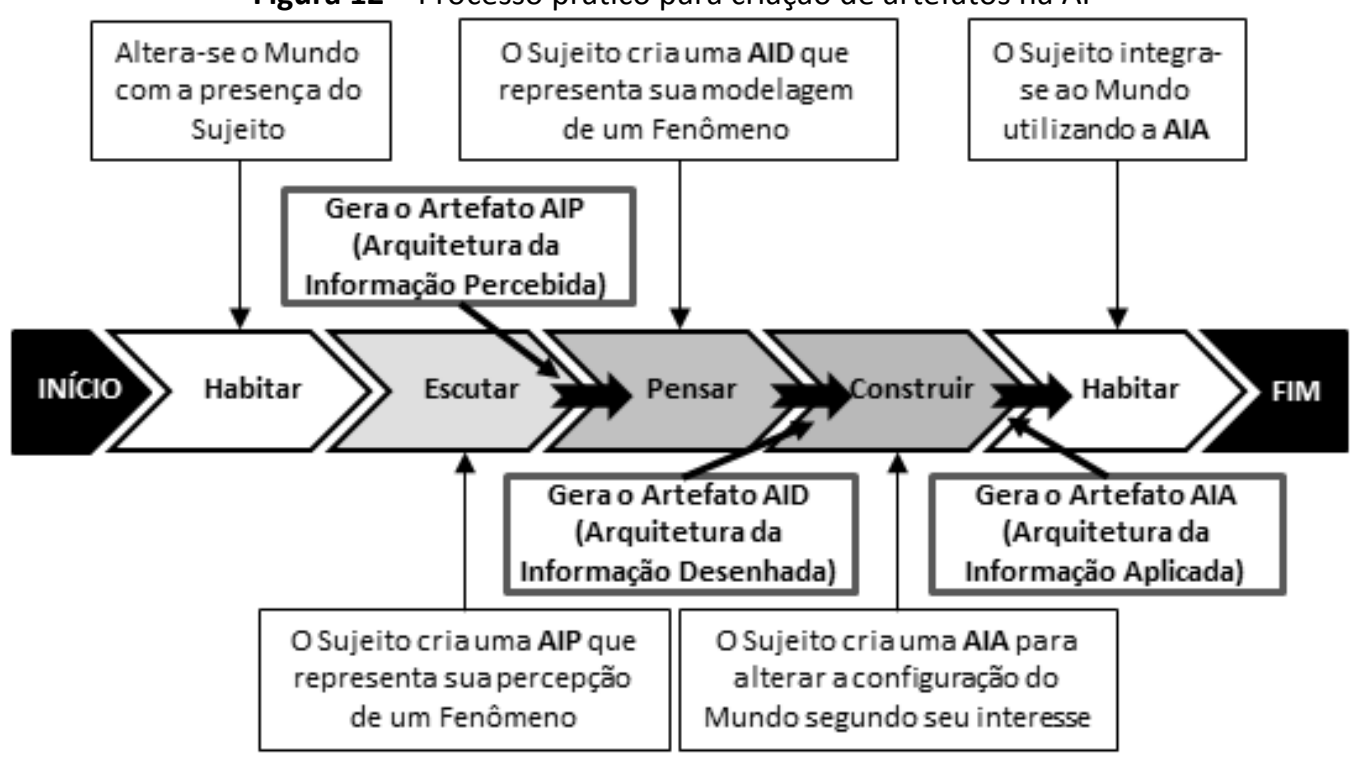

Fonte: adaptado de Siqueira (2012)

\subsubsection{Arquitetura da Informação Organizacional (AIO)}

AlO tem sua origem na discussão sobre a Enterprise Information Architecture, com o trabalho de Zachman (1987), que defende a importância de se definir arquiteturas de informação para promover a integração dos diferentes tipos de sistemas existentes nas organizações:

Com o aumento do tamanho e da complexidade das implementações de sistemas de informação, é necessário o uso de construções lógicas (ou arquitetura) para definir e controlar as interfaces e a integração de todos os componentes do sistema.

A principal preocupação ao se adotar uma AlO era promover a integração entre os sistemas da organização, que proliferaram em número e complexidade a partir dos avanços das Tecnologias da Informação e Comunicação.

Duarte (2010, p. 42) identifica diferentes definições para AIO, mas todas elas focam na integridade das informações manipuladas em diferentes sistemas. Segundo este autor, a AIO é um processo de documentação dos elementos da organização que permite gerenciar as mudanças, estabelecendo controles entre a situação atual e a situação desejada e abrangendo diferentes domínios da organização.

O objetivo da AIO é modelar, analisar e comunicar a estrutura da informação na forma

Perspectivas em Gestão \& Conhecimento, João Pessoa, v. 7, n. 2, p. 122-159, jul./dez. 2017. 
como ela está implementada em diferentes sistemas organizacionais, tanto automatizados como processados manualmente. Esta iniciativa se propõe a promover o alinhamento de recursos, a governança da informação, a criação de políticas, a vigilância dos recursos empregados, a caracterização de uma visão da estratégia corrente e futura e a definição de um plano de mudança para implementar a arquitetura desejada para a organização (DUARTE, 2010, p. 43-44).

A Figura 13 apresenta a posição da AIO na estratégia organizacional. Ela caracteriza um programa de governança de recursos que usa a modelagem conceitual com o objetivo de promover a governança da informação corporativa. A arquitetura empresarial é apresentada como o elemento chave para integrar os recursos organizacionais, de modo a garantir a execução da estratégia da organização. Para tanto, ela desenvolve e integra diferentes tipos de modelos.

Figura 13 - Posição da Arquitetura da Informação Organizacional na concepção empresarial

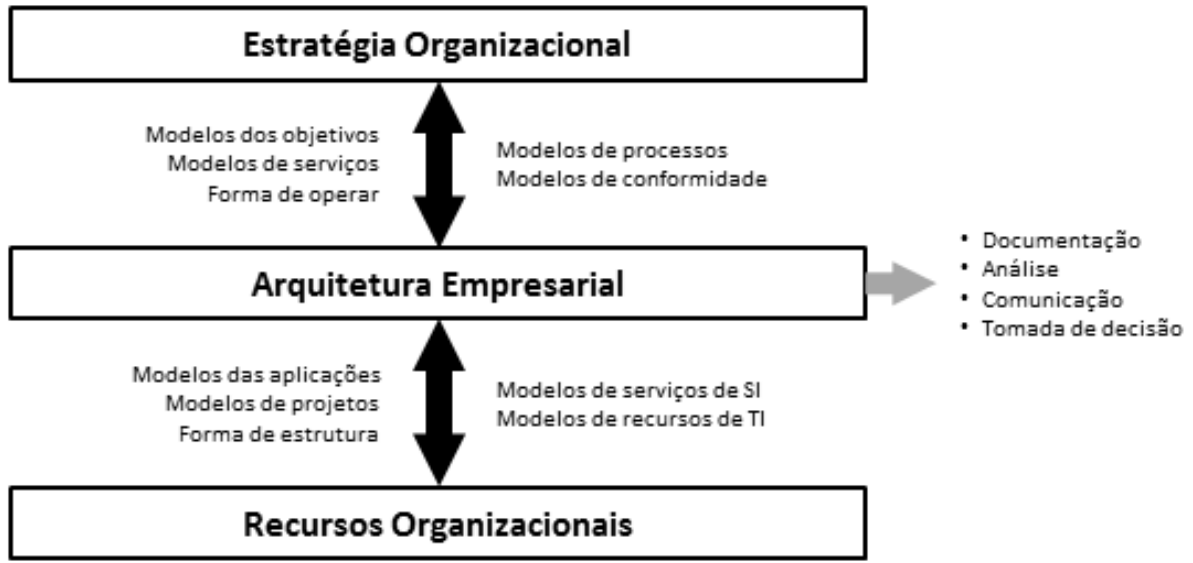

Fonte: Duarte (2010, p. 46)

Duarte (2010) identifica diferentes abordagens para a implementação da AIO, conforme apresentado no Quadro 2.

Quadro 2 - Diferentes perspectivas para a Arquitetura da Informação Organizacional

\begin{tabular}{|l|l|}
\hline \multicolumn{1}{|c|}{ Perspectiva } & \multicolumn{1}{c|}{ Descrição } \\
\hline AIO como estratégia & $\begin{array}{l}\text { Apresenta os elementos essenciais da organização e seus } \\
\text { relacionamentos }\end{array}$ \\
\hline $\begin{array}{l}\text { AIO como modelagem } \\
\text { organizacional }\end{array}$ & $\begin{array}{l}\text { Apresenta uma estrutura abrangente dos modelos utilizados em } \\
\text { diversos domínios organizacionais. É baseada no conceito de Zachman } \\
(1987) .\end{array}$ \\
\hline $\begin{array}{l}\text { AIO como métodos e } \\
\text { padrões }\end{array}$ & Frameworks, padrões e métodos para a modelagem de uma AIO. \\
\hline AIO como pontos de vista & $\begin{array}{l}\text { Apresenta propostas de diferentes pontos de vista para a modelagem } \\
\text { da AIO. }\end{array}$ \\
\hline AIO como conteúdo & Cria uma infraestrutura para acesso a modelos da AIO. \\
\hline $\begin{array}{l}\text { AIO como linguagem para a } \\
\text { arquitetura }\end{array}$ & $\begin{array}{l}\text { Propõe um conjunto de padrões e um vocabulário controlado para a } \\
\text { criação de uma AlO. }\end{array}$ \\
\hline AIO como ontologia & Cria uma ontologia de elementos de negócio, aplicações e tecnologias. \\
\hline
\end{tabular}

Fonte: Adaptado de Duarte (2010)

Duarte (2010) propõe, ainda, um método de construção de Arquiteturas da Organização Ágeis (2AIO), que tem como objetivos: (i) tornar acessível a todos na organização o domínio de sua estrutura, (ii) refletir, no menor espaço de tempo possível, a disposição atual 
dos diversos elementos que compõem a organização; (iii) permitir o desenho de novos arranjos dos elementos e (iv) permitir que a disposição dos elementos que compõem a organização reflita, no menor espaço de tempo possível, uma estrutura desejada. E destaca:

\footnotetext{
[...] a proposta $2 \mathrm{AIO}$ adota uma ontologia com termos e relações. Essa ontologia retrata a organização, com seus elementos e relacionamentos. A ontologia é definida e mantida de forma colaborativa. Para tanto, é disponibilizado um ambiente de navegação que permite acesso à ontologia e colaboração na manutenção de suas instâncias. A navegação permite acesso a termos e relações e também a modelos gráficos que representam a mesma informação.

[...] O modelo $2 \mathrm{AlO}$ considera que as organizações possuem diversas comunidades que modificam a sua estrutura e que as ações que resultam nas modificações acontecem a todo instante, em qualquer lugar, executadas por pessoas independentemente de suas posições ou cargos. A 2AIO, por meio da ontologia organizacional, une as pessoas que definem, as que desenham e as que agem sobre a estrutura organizacional, integrando os mundos do negócio, das aplicações e da tecnologia. (DUARTE, 2010, p. 156159).
}

O uso de ontologias na composição de soluções de AIO possibilita um mapeamento adequado do Espaço da Informação Organizacional e impulsiona tanto as iniciativas de governança corporativa quanto a criação de um referencial epistemológico adequado para a GC e a criação de Sistemas de Informação na Organização (ALBANI; DIETZ, 2011; ISBANDI; ALBARDA, 2013; BETZ; PHILLIPS, 2015). As abordagens da AIO fundamentam-se em uma perspectiva que parte de considerações sobre ontologias, tema tratado a seguir.

\subsection{Ontologias}

Ontologias são estudadas por um ramo da Filosofia interessada nos entes que existem. Ontologias têm sido utilizadas para tratar algumas deficiências encontradas na representação do conhecimento de um domínio. Isso ocorre, principalmente, devido à sua característica de ser compartilhável e independente da aplicação, podendo, assim, ser utilizada por diversos sistemas. Ontologia foi definida por Aristóteles como o estudo do ser enquanto ser; como parte da Metafísica. Encontram-se nos filósofos antigos alguns rudimentos de um estudo do ser, mas sem distinguir esta disciplina de outras, nem the dando nome específico. (LIMAMARQUES, 2006)

A referência moderna ao termo ontologia surge em 1646 e o filósofo alemão Johann Clauberg traduz literalmente como o nome grego óntos (ente), apondo-lhe o sufixo logia (ciência).

É importante distinguir ontologia como área da Filosofia que estuda os seres (entes) e suas respectivas naturezas de seu uso corrente, em particular na Ciência da Computação e na Ciência da Informação, como um mapeamento de conceitos existentes em um domínio específico, também denominada de ontologia de domínio. No restante deste texto o termo ontologia refere-se ao conceito de ontologia sob essa perspectiva.

Pode-se entender a ontologia como:

[...] uma especificação explícita de uma conceitualização. [...] Em tal ontologia, definições associam nomes de entidades no universo do discurso (por exemplo, classes, relações, funções etc. com textos que descrevem o que os nomes significam e os axiomas formais que restringem a interpretação e o uso desses termos). (GRUBER, 1995) 
Guizzardi (2007) considera uma ontologia como sendo um artefato computacional composto por um vocabulário de conceitos, suas definições e propriedades, um modelo gráfico que mostra as relações entre os conceitos e um conjunto de axiomas formais para restringir a interpretação dos conceitos e relações.

Existem algumas características básicas para o uso de ontologias como forma de representar conhecimento e de se obter as informações relacionadas aos conceitos concernentes. Em geral, uma ontologia deve: (i) definir uma hierarquia de conceitos; (ii) estabelecer atributos ou propriedades inerentes ao conceito representado por uma classe; (iii) estabelecer relações entre os conceitos; (iv) possibilitar a elaboração de sentenças para restringir inferências de conhecimento baseadas na estrutura.

Guizzardi (2007) realizou um estudo sistemático das relações entre uma linguagem de modelagem e o conjunto de fenômenos observados em diferentes domínios do mundo real. Ele avalia a adequação - no caso específico, a adequação de uma ontologia - como medida de representação conceitual de um domínio (sobre o qual uma ontologia foi criada).

Guizzardi (2007) discute ontologia de referência que podem ser utilizadas como fundamento conceitual, denominada ontologia fundacional (ou de fundamento), para a descrição de conceitos básicos em representações conceituais. $O$ autor propõe as bases para a representação de modelos de conceituação estruturais - modelos de domínio, modelos de informação, modelos semânticos de dados, entre outros.

Sowa (2000, p. 51-131) faz uma análise das ontologias como modelos de representação do conhecimento. Segundo ele, ontologias definem as categorias de domínio; descrevem os elementos que existem. $O$ autor faz uma apreciação de diferentes modelos de ontologias. Compara as propostas de Aristóteles, Kant, Husserl, Peirce, Whitehead e Heidegger para identificar que existe uma estrutura comum nos modelos de representação ontológicos. Todos eles compreendem o conceito de um tipo universal primitivo e se especializam em entes físicos e entes abstratos e relacionam os conceitos de independência, relatividade e mediação para criar o que ele considera a matriz das doze categorias centrais aplicadas na representação do conhecimento (Quadro 3).

\begin{tabular}{|c|c|c|c|c|}
\hline \multirow{5}{*}{$\begin{array}{r}\text { Independente } \\
\text { Relativo } \\
\text { Mediatizado }\end{array}$} & \multicolumn{4}{|c|}{$\begin{array}{c}\text { Quadro } 3 \text { - Matriz de categorias identificadas por Sowa } \\
\text { Fisico }\end{array}$} \\
\hline & Continuante & Ocorrente & Continuante & Ocorrente \\
\hline & Objeto & Processo & Esquema & Script \\
\hline & Juntura & Participação & Descrição & História \\
\hline & Estrutura & Situação & Razão & Propósito \\
\hline
\end{tabular}

Um aspecto importante na classificação de Sowa é o uso de linguagens para capturar os elementos de uma ontologia. Ele se utiliza intensivamente dos conceitos e da linguagem da Matemática como instrumentos de representação dos conceitos envolvidos em uma ontologia. Fazendo uso de tais conceitos e linguagem, estabelece axiomas para a delimitação de entes físicos e abstratos. Ele distingue Continuants de Ocorrents. Para ele, um Continuant é um objeto que existe no tempo e do qual não é possível dizer que ele possui fases ou partes temporais, pois a todo tempo o Continuant está presente (p. 118). Um Ocorrent, por outro lado, descreve uma categoria de elementos que possuem partes temporais, fases sucessivas, distinguidas no tempo.

Em sua busca por conceitos primitivos em ontologia, Sowa conclui que a Teoria dos Conjuntos e a Mereologia - a primeira aplicada a entes contáveis e a segunda a entes não contáveis - são duas teorias matemáticas para a descrição e a definição de conceitos e relações de natureza ontológica. Por fim, indica a investigação sobre os fundamentos da linguagem como essencial para a compreensão das diversas ontologias utilizadas. Sowa afirma: 
A teoria dos conjuntos e a mereologia são duas teorias matemáticas que fornecem primitivas para a definição de conceitos e relações. Elas também têm sido combinadas com outras teorias, como a topologia e mereologia todo-parte para formar mereotopologia. Outra fonte rica de primitivas está nos vocabulários e estruturas sintáticas que as pessoas têm achado útil para falar sobre o mundo. Linguistas como Leonard Talmy $(1983,1996)$ e Anna Wierzbicka (1996) vêm analisando os vocabulários de diversos idiomas para encontrar as primitivas universais que as pessoas usam para descrever relações. Outros pesquisadores têm vindo a aplicar as teorias formais para a definição de palavras informais de descrição do espaço, como dentro e através. Em sua pesquisa de raciocínio espacial qualitativo, Anthony Cohn (1997) descreveu a riqueza das relações espaciais e da variedade de teorias que as pessoas têm desenvolvido para raciocinar sobre elas. Teorias formais podem definir um número infinito de estruturas e os estudos empíricos sobre a linguagem e o mundo são necessários para determinar quais são os mais úteis, relevantes e expressivos (SOWA, 2000, p. 123).

Dietz (2006) defende que a criação de uma ontologia organizacional é importante para os gestores, os colaboradores e os clientes da organização. Para argumentar sobre esta importância, o autor apresenta fundamentos conceituais sobre o que é a ontologia e analisa a construção do conhecimento organizacional como a criação de um modelo ontológico da realidade, considerando estados, transições entre estados e eventos que causam mudanças de estados. $\mathrm{O}$ autor faz a distinção entre os aspectos funcionais (orientados a comportamentos) e os aspectos construtivos (orientados a operações) e mostra que esta distinção corresponde a dois modelos de representação de sistemas organizacionais: (i) modelos de caixa preta (funcionais) e (ii) modelos de caixa branca (operacionais).

Com base em uma específica noção de modelagem organizacional, o autor caracteriza o papel da ontologia como instrumento de desenvolvimento dos sistemas corporativos, em particular para aqueles sistemas que manipulam informações. Sobre estes aspectos, o autor desenvolve o conceito de uma engenharia organizacional baseada em ontologia. $O$ fundamento de seu modelo é o que ele denomina teoria $\varphi(\mathrm{FI})$, que relaciona fatos a informações. Fatos e informações determinam o modo como os atores organizacionais desempenham seus papeis na organização, em particular para cumprirem a missão institucional e realizarem os objetivos estratégicos definidos para ela.

Dietz analisa a relação entre os papéis organizacionais e as habilidades humanas para construir e manipular dados (formar), raciocinar (informar) e executar/inovar (performar). Para isto ele faz uso da perspectiva Linguagem-Ação, um campo científico que pretende relacionar a relação entre a representação de conceitos a partir da linguagem e seus impactos nas ações humanas.

Usando as relações entre os atores organizacionais, suas habilidades de formar, informar e performar, Dietz propõe um método de construção da ontologia organizacional que inclui quatro modelos:

- O modelo de construção apresenta a estrutura da organização em termos de suas funções; papeis executores e níveis de interação entre os papeis organizacionais para a execução das funções organizacionais;

- O modelo de processos apresenta as diferentes transações que ocorrem dentro da organização e suas inter-relações como causa ou como condição para a efetivação de um valor organizacional. $\mathrm{O}$ modelo de processo classifica ontologicamente as transações que ocorrem dentro de uma organização. Uma transação é causa quando ela é precondição para outra e é condição quando é necessário que ela seja concluída para que outra inicie.

- O modelo de ações descreve o conjunto de ações e suas regras para que a organização

Perspectivas em Gestão \& Conhecimento, João Pessoa, v. 7, n. 2, p. 122-159, jul./dez. 2017. 
execute seu papel institucional. Apresenta uma espécie de algoritmo organizacional

- O modelo de estados apresenta o espaço de estados da organização com base em ações que realizam e ações que se comprometem para a realização, além de identificar os elementos que são produzidos e os que são utilizados nas diferentes ações organizacionais.

\section{MÉTODO}

O objetivo desta seção é apresentar: (i) o método no qual esta pesquisa se enquadra, (ii) a visão de mundo adotada como referencial para exame do problema de pesquisa, (iii) o percurso metodológico estabelecido para atingir os objetivos delineados e (iv) as fontes de informação utilizadas para fundamentar a revisão de literatura.

Uma pesquisa é definida como um procedimento racional e sistemático que tem como objetivo proporcionar respostas aos problemas que são propostos (GIL, 2002). Esta pesquisa se alinha a esse conceito, uma vez que o percurso metodológico estabelecido é utilizado para alcançar os objetivos gerais e específicos em resposta ao problema proposto.

Essa pesquisa é de natureza teórica e analítica, visando caracterizar as contribuições da Al como fundamento epistemológico para o uso da ontologia de domínio como ferramenta de GC nas organizações.

A pesquisa usa a abordagem fenomenológica. Através do método de análise fenomenológica, visa-se ressaltar as propriedades dos fenômenos observados de um determinado ponto de vista teórico. A pesquisa se caracteriza como eminentemente qualitativa, com aspectos exploratórios. Parte do ponto de vista do Sujeito, suas crenças e valores como fundamentos de um arcabouço teórico que the permite ver o mundo e construir instrumentos de interação com ele.

Bunge (1980) insiste que toda teoria científica pressupõe uma determinada ontologia da realidade. Uma visão de mundo é uma declaração de quais conceitos são adotados para examinar o problema dentro de uma investigação científica. A declaração de uma visão de mundo tem o propósito de situar o referencial utilizado pelo pesquisador em relação à abordagem filosófica adotada, a qual interfere diretamente na posição epistemológica escolhida e no conceito dos experimentos e problemas que a pesquisa pode utilizar em seu método científico.

Neste trabalho, adota-se a perspectiva filosófica construída para investigações em torno da Al (SIQUEIRA, 2012) a partir da proposta de Gigch e Pipino (1986). A Figura 14 representa o modelo de Gigch e Pipino (1986) como uma estrutura de abordagem filosófica para problemas relacionados a sistemas de informação, mas que podem ser estendidos para outros problemas. Nela se apresenta uma visão de mundo que considera um percurso conceitual entre a epistemologia e a prática. A visão de mundo apresentada por Gigch e Pipino (1986) tem início com uma determinada postura assumida a partir da Filosofia da Ciência, a qual seria o fundamento para o estabelecimento de uma epistemologia referencial. Com a definição de uma epistemologia assume-se certo paradigma (KUHN, 2003), o qual disciplina os procedimentos científicos que serão adotados. O resultado desta perspectiva científica é um conjunto de teorias e modelos. O resultado das teorias e modelos e a definição de uma determinada prática (práxis) científica, a qual passa a ser aplicada como referencial para a construção de instrumentos tecnológicos que visam a solução de problemas.

Siqueira (2012) propõe que a adoção da visão de mundo de Gigch e Pipino (1986) necessita de um desdobramento adicional para que se constitua em um referencial adequado para a apreciação da Al como disciplina científica. Ele propõe que se acrescentem as dimensões da Ontologia e da Fenomenologia como fundamentos para a caracterização de uma determinada Filosofia da Ciência para a Arquitetura da Informação, como apresentada na Figura 15. A ontologia define os entes que devem ser considerados como referenciais para

Perspectivas em Gestão \& Conhecimento, João Pessoa, v. 7, n. 2, p. 122-159, jul./dez. 2017. 
uma abordagem da Al. A fenomenologia é tomada como perspectiva filosófica para uma exploração das relações entre os entes definidos na ontologia. A partir de uma ontologia e com a abordagem fenomenológica, caracteriza-se uma determinada epistemologia, início da Metamodelagem (M3) proposta por Gigch e Pipino (1986).

Figura 14 - Visão de mundo - Metamodelo M3

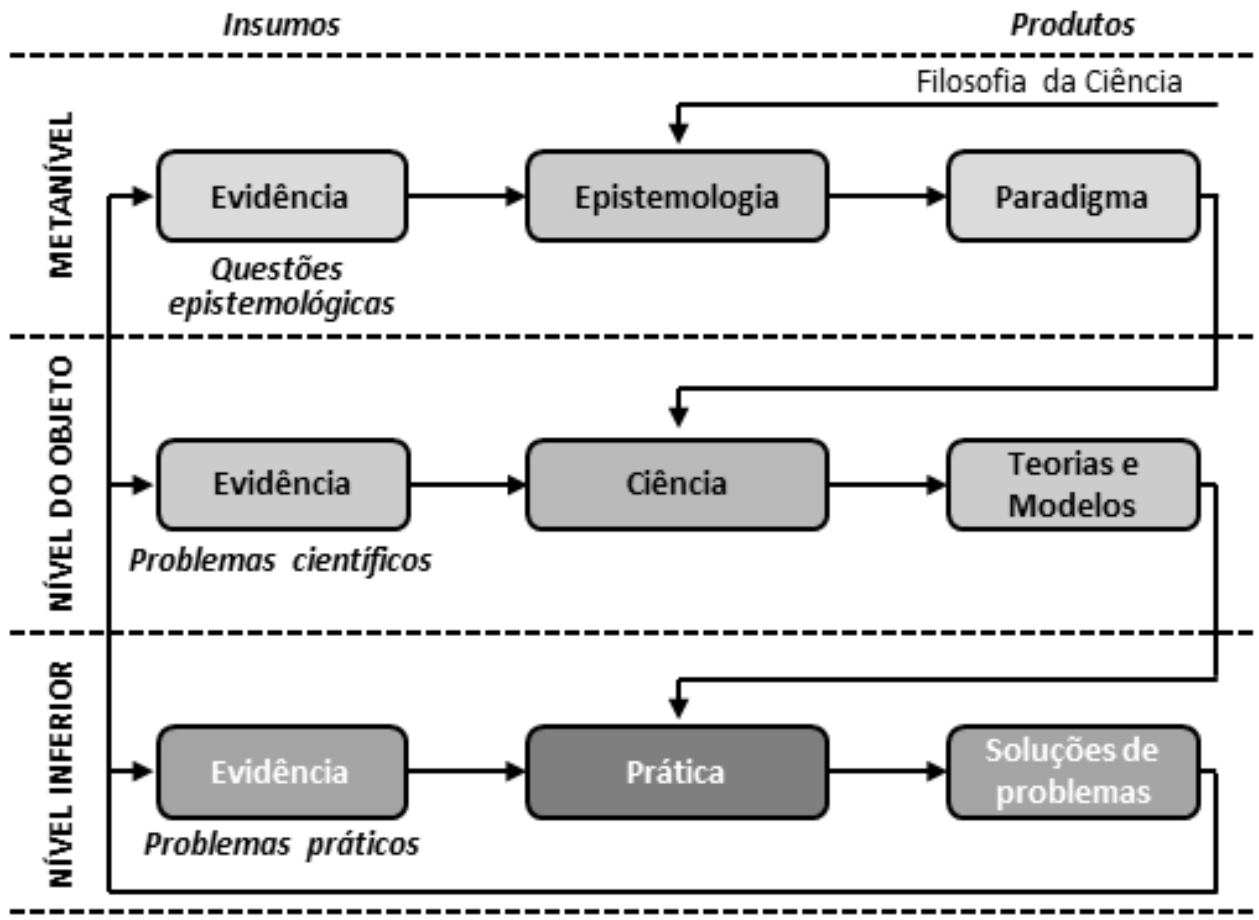

Fonte: Adaptado de Gigch e Pipino (1986)

Figura 15 - Visão de mundo - Do nível ontológico ao tecnológico

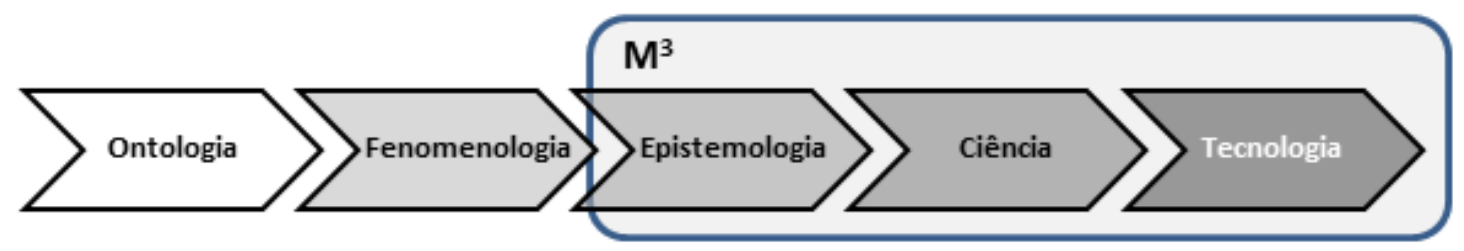

Fonte: Siqueira (2012)

Esta pesquisa assume os aspectos filosóficos de uma ontologia para a Al e adota a perspectiva fenomenológica e o referencial epistemológico proposto por Siqueira (2012). Ao realizar um levantamento bibliográfico para uma compreensão dos fundamentos da Arquitetura da Informação Organizacional (AIO) e da GC, esta pesquisa situa-se no nível da ciência e, ao pretender identificar aplicações e usos para a Al nas práticas de GC, ela também se situa no nível tecnológico.

Assume-se que os objetivos específicos apresentados constituem os elementos necessários e suficientes para se alcançar o resultado pretendido. Desta forma, o percurso metodológico realizado foi: (i) caracterização dos conceitos de Al e GC via revisão bibliográfica; (ii) identificação das práticas de criação de ontologias pelos paradigmas tecnológicos existentes; (iii) caracterização das contribuições da Al para o desenvolvimento de ontologias como ferramentas para práticas de GC.

As fontes de informação utilizadas para a identificação de documentos relevantes para a revisão bibliográfica realizada neste trabalho foram: (i) a biblioteca da UCB, por meio de seu 
acervo físico e digital, incluindo seu banco de dados de teses e dissertações; (ii) o banco de teses da CAPES; (iv) o portal de periódicos da CAPES; (v) o Google Acadêmico.

\section{RESULTADOS}

Neste capítulo, são apresentados os seguintes resultados: (i) um conjunto de orientações da Al para a construção de ontologias de domínio e (ii) os fatores críticos de sucesso para o uso de ontologias de domínio - dentro dos padrões propostos pela Al - como instrumentos de GC organizacional.

\subsection{Uso da Al para construção de ontologias de domínio}

Nesta seção, destacam-se as orientações da Al para a construção de ontologias de domínio. Partindo da abordagem filosófica, científica e tecnológica proposta por Siqueira (2012), utiliza-se o MAIA como referencial de aplicação da Teoria Geral de AI (COSTA, 2009). A abordagem proposta pretende utilizar um processo prático para criação de artefatos na Al.

\subsubsection{O uso do MAIA na construção de ontologias de domínio}

MAIA (COSTA, 2009), por ser um método de construção de arquiteturas da informação, aplica-se também no contexto organizacional. O modelo integra os princípios epistemológicos e científicos para a construção de uma abordagem teórica que visa representar um espaço de informação segundo o ponto de vista de um sujeito determinado, sendo, portanto, um método fenomenológico.

MAIA prevê quatro momentos: o Escutar, o Pensar, o Construir e o Habitar. São momentos de atuação do sujeito sobre o espaço de informação. O Escutar e o Pensar são voltados para os aspectos abstratos deste espaço. O Construir e o Habitar são momentos voltados para os aspectos concretos. O Pensar concentra a modelagem hermenêutica de um espaço de informação. O Construir reúne as ações de manipulação dos elementos de um espaço de informação. O Habitar é o momento em que o sujeito usa o espaço de informação percebido, modelado e aperfeiçoado conforme suas intenções. Os procedimentos gerais de cada momento são:

- Escutar. É o primeiro momento de delimitação e organização do espaço de informação. Ele é composto pelo ato de ouvir e pelo ato de interpretar, que geram significados para os registros captados e determinam a intenção do sujeito ao adaptar-se a um espaço de informação.

- Pensar. É uma rotina de análise de registros que produz redes de significados organizados e aptos a representar o espaço de informação, composto pelos atos de interpretar e desenhar.

- Construir. É um conjunto de ações finitas e planejadas que servirão de base para a transformação do espaço de informação.

- Habitar. É a incorporação de espaço de informação pelo sujeito pelos atos de transformar e estar.

Para cada um destes momentos é possível derivar procedimentos específicos para a construção das ontologias de domínio.

\subsubsection{Orientações derivadas da aplicação do MAIA}

Com a aplicação dos conceitos de Escutar, propostos em MAIA, neste momento devese:

- Fazer o registro da percepção que os sujeitos possuem do Espaço de Informação. O 
resultado desta prática deverá ser uma definição dos critérios que delimitam o domínio de interesse para o qual uma ontologia de domínio será construída.

- Definir os critérios que delimitam o espaço de interesse do domínio. Como resultado obtémse: (i) o registro dos itens atendidos pelos critérios estabelecidos; e (ii) registros do estado da ontologia de domínio candidata.

Os conceitos relativos ao momento Pensar permitem extrair as seguintes orientações:

- Identificar os conceitos chave no espaço de informação caracterizado. O resultado desta prática é uma coleção de itens que são candidatos a classes fundamentais na ontologia de domínio.

- Aplicar os critérios definidos aos itens colecionados. O resultado desta prática é a caracterização do pertencer ou não ao domínio de interesse.

- Caracterizar cada um dos elementos aprovados segundo os critérios de seleção identificados. A caracterização resultará em uma coleção de entes adequadamente identificados com seus atributos e relacionamentos definidos. Estes entes representam o domínio que se pretende modelar.

Os conceitos relativos ao momento Construir permitem extrair as seguintes orientações:

- Transformar cada conceito chave identificado e caracterizado em uma classe, um atributo ou em um relacionamento dentro do modelo da ontologia.

- Garantir que todos os atos de transformação executados no domínio sejam realizáveis por meio dos elementos descritos no modelo proposto para a ontologia.

- Exercitar a modelagem estática. Todos os elementos existentes e significativos no Espaço de informação modelado devem ser descritos em termos da ontologia proposta de forma direta, ou por meio da composição dos entes discriminados na ontologia (entes compostos).

- Exercitar a modelagem dinâmica. Todos os procedimentos existentes e significativos no Espaço de Informação devem ser passíveis de execução, utilizando-se os elementos modelados na ontologia. Deste modo, testa-se como as ações e operações existentes no espaço de informação podem ser representadas através dela.

- Implementar a ontologia via uma tecnologia de representação da informação que seja adequada ao problema e para a qual a organização já esteja adaptada.

Para aplicar os conceitos relativos ao Habitar deve-se observar as seguintes orientações:

- Certificar-se que os usuários compreenderam a ontologia e não apenas a tecnologia envolvida durante o processo de implantação da tecnologia que representa o Espaço de Informação modelado.

- Criar um espaço de aprendizado do modelo. Um modelo não compreendido poderá resultar em uso inadequado e introdução de sérios problemas organizacionais.

- Buscar elementos que possam aperfeiçoar a ontologia criada, após o seu uso. Esta busca reinicia o ciclo de aprimoramento da Al criada. Isto fará retornar a um novo ciclo EscutarPensar-Construir-Habitar, correspondendo a um ciclo de melhoria da ontologia proposta.

\subsection{A proposta da ontologia organizacional de lan Dietz}

Como elemento comparativo da consistência da proposta apresentada pelo CPAl, fazse um breve relato da proposta de Dietz (2006) para a construção de ontologias organizacionais. Para ele, a organização é um espaço de interações de informações ou, na linguagem do CPAI, um Espaço de Informação.

Para a construção de uma ontologia empresarial, Dietz propõe a adoção de três 
perspectivas:

- A perspectiva $\varphi$ (fi) - A todo fato corresponde uma informação.

- A perspectiva $\tau$ (tao) - A informação empresarial organiza-se em uma hierarquia de três níveis: (i) o nível da Ontologia, que captura a essência da informação; (ii) o nível da Arquitetura, que modela a informação de modo a representar a própria organização; (iii) o nível da Tecnologia, que transforma o modelo em um instrumento de uso dentro da organização.

- A perspectiva $\psi$ (psi) - Nesta perspectiva, os agentes da organização são classificados segundo os tipos de interações sociais que eles executam (PSI = Perform Social Interactions). As interações sociais são equivalentes aos Atos de Transformação propostos pelo CPAI.

O que se observa na proposta da Ontologia Corporativa é que o tema pode ser bem descrito utilizando-se os instrumentos conceituais (constructos) do CPAI.

A perspectiva $\varphi$ pode ser descrita como a relação entre um Espaço de Informação e os elementos percebidos pelo Sujeito dentro dele.

A perspectiva $\tau$ corresponde a uma primeira transformação na configuração do Espaço de Informação pela introdução de um modelo de representação que cobre os níveis Filosófico (Ontologia), Científico (Arquitetura) e Tecnológico (Tecnologia).

A perspectiva $\psi$ corresponde a uma dinâmica de transformação do Espaço de Informação através do uso dos Atos de Transformação.

Considerando que a Ontologia Empresarial proposta por Dietz corresponde a um sofisticado mecanismo de representação de conteúdos organizacionais, a cobertura do poder representativo deste modelo pelo proposto pelo CPAI oferece a este último uma validação relativa ao uso. Cabe destacar que este modelo é mais amplo devido ao uso do conceito fenomenológico que coloca toda a perspectiva organizacional em função do Sujeito e de suas percepções. Além disso, os fundamentos filosóficos, científicos e tecnológicos são mais sólidos do que os demais.

\subsection{Fatores críticos de sucesso para o uso de ontologias de domínio}

A criação de uma ontologia é um processo cuja essência é caracterizada pelo conjunto de escolhas que permitem definir conceitos para um domínio específico sob observação. A própria ontologia é um grupo de especificações formais sobre quais semânticas devem ser recuperadas quando determinado signo ou símbolo é apresentado.

O problema tem suas raízes na Filosofia com a busca pela essência das coisas ou seres e desdobra-se na Linguística por meio dos esforços da Onomasiologia e da Semasiologia.

Pelo estudo da significação, cuja metodologia de análise parte das noções ou conceitos para determinar as formas linguísticas a eles correspondentes, a Onomasiologia realiza, no campo da Linguística, a determinação das representações adequadas para os conceitos. Por outro lado, a Semasiologia caracteriza-se como estudo da significação cuja metodologia de análise parte das formas linguísticas para indicar as noções ou conceitos a elas correspondentes.

Do ponto de vista linguístico, uma ontologia é resultado de um esforço onomasiológico, na medida em que a sua criação estuda as noções e conceitos existentes em um domínio e os caracteriza na forma de classes, subclasses, propriedades, atributos e instâncias.

O desenvolvimento de uma ontologia, de um modo geral, inclui: (i) definir as classes na ontologia; (ii) organizar as classes em uma hierarquia taxonômica; (iii) definir slots e descrever os valores que podem conter; (iv) preencher os valores dos slots para as instâncias.

Identificar classes, organizá-las hierarquicamente e definir os atributos e propriedades 
que as qualificarão não é uma tarefa trivial. Que critérios devem ser utilizados para caracterizar uma classe? Como decidir se um elemento do domínio deverá aparecer como uma classe ou como um slot? Como modelar relacionamentos entre elementos? Essas e outras questões exigem uma atenção mais detalhada em como se deve proceder ao modelar uma ontologia. O primeiro passo neste processo é reconhecer qual a visão de mundo que existe no domínio - em outras palavras, existe uma filosofia que caracteriza o modelo compartilhado pelos usuários do domínio?

Em seu conceito de $\mathrm{Al}$, o CPAl propõe o uso de três níveis conceituais na modelagem do conhecimento: (i) o nível Filosófico, Epistemológico ou de Meta-modelagem corresponde aos conceitos aceitos dentro de determinado ramo do conhecimento e que lhe constitui a base conceitual de discussão. (ii) o nível Científico, Tático ou de Modelagem corresponde aos conceitos que possibilitam a modelagem dos fenômenos observáveis no domínio e que atendem às noções caracterizadas no nível anterior, mas criando uma nova ordem de conceitos que podem ser observados dentro de uma determinada realidade. (iii) O nível Prático, Operacional ou de Aplicação - corresponde ao conjunto de conceitos que derivam dos níveis anteriores e que possibilitam o uso efetivo dos conceitos em aplicações experimentais ou uso tecnológico. Como ontologias podem são vistas como uma forma de representação do conhecimento, é natural que sua estruturação possa se valer desses três níveis.

\subsubsection{Utilizando os princípios filosóficos}

O uso das categorias aristotélicas pode nortear o processo de decisão quanto ao esforço de identificação dos conceitos chave presentes em um domínio. Nos trabalhos de Aristóteles identifica-se um esforço de classificação de conceitos baseados em classes de palavras. Dentro do sentido que continham, as palavras podem ser classificas em categorias. No universo aristotélico, têm-se os seguintes sentidos da ideia e suas respectivas categorias: (i) o quê (substância); (ii) o quanto (quantidade); (iii) o como (qualidade); (iv) com que se relaciona (relação); (v) onde está (lugar); (vi) quando (tempo); (vii) como está (estado); (viii) em que circunstância (hábito); (ix) atividade (ação - logos); (x) emoção (paixão - pathos).

Toda ontologia é uma restrição da realidade por ser dela um modelo. Este modelo expressa na verdade a compreensão que um sujeito ou comunidade possui acerca do domínio observado e modelado. O papel da fenomenologia é fundamental. Cada sujeito tem um ponto de vista individual, portanto deve-se optar por um Sujeito Corporativo, constituído por visões compartilhadas entre os sujeitos individuais na organização.

Não existe o caminho correto para se modelar um domínio, mas alternativas viáveis. A melhor solução sempre depende da aplicação que se tem em mente e das extensões que podem ser visualizadas antecipadamente.

Dentro de muitas alternativas viáveis, é preciso determinar aquela que desempenhará melhor a tarefa projetada, que seja mais intuitiva, mais expansível e que ofereça melhor manutenibilidade. É preciso também recordar que uma ontologia é um modelo da realidade existente e que os conceitos nesta ontologia devem refletir tal realidade.

Diante das diferentes possibilidades de representação, deve-se considerar que uma determinada definição de classes de um domínio reflete um juízo sobre tal realidade. Em particular, estas classes, primariamente, representam substâncias, segundo Aristóteles. Uma instância é um exemplo de classe ou subclasse.

O ciclo de vida de uma ontologia pode ser vista, no contexto do CPAI, dentro dos seguintes parâmetros: (i) escolha de uma epistemologia (Nível 1); (ii) modelagem de uma especificação explícita que corresponde à imagem da realidade (Nível 2); (iii) uso da ontologia para os domínios cobertos por ela e para um determinado conjunto de questões de competências (Nível 3).

Perspectivas em Gestão \& Conhecimento, João Pessoa, v. 7, n. 2, p. 122-159, jul./dez. 2017. 


\subsubsection{Utilizando os princípios científicos}

A construção de ontologias é uma atividade executada sobre um Espaço de Informação. Deste modo, as ideias propostas pelo CPAl são aplicáveis a esta atividade. Detalhadamente, a construção de uma ontologia significa: (i) Identificar o propósito, (ii) Construir uma ontologia (capturá-la, codificá-la e integrá-la com ontologias existentes); (iii) Avaliar a ontologia; (iv) Documentar a ontologia

A adoção de uma visão de mundo, como primeiro passo do processo, permite identificar os conceitos existentes no domínio de modo independente de sua aplicação e garante que os conceitos, fundamentalmente, refletem algo próximo da realidade, dentro de determinado ponto de vista. Esta etapa de caráter epistemológico equivale aos esforços de captura de uma ontologia e sua documentação.

Destaca-se, em particular, a necessidade de documentar explicitamente a representação dos conceitos que estão sendo utilizados na definição da ontologia. Deverão ser documentadas todas as premissas utilizadas na especificação dos conceitos, além das ideias fundamentais que direcionaram tal ou qual escolha. Esta posição justifica-se diante da necessidade de compartilhar determinado ponto de vista. Tais questões estão diretamente relacionadas a um nível epistemológico, podendo ser tratadas previamente.

O passo seguinte da especificação de uma metodologia representa o esforço de descrever formalmente as escolhas dos conceitos chave e de seus relacionamentos e propriedades. Ao utilizar o critério aristotélico, é possível identificar substâncias ou substantivos como candidatos à condição de classes dentro de uma ontologia, e as relações estabelecidas entre elas caracterizarão atributos e propriedades dentro dos seguintes critérios: (i) uma propriedade é uma qualidade, relação, ação ou paixão da substância; (ii) um atributo é um lugar, um tempo, um estado ou uma circunstância. Esta atividade corresponde à codificação da ontologia e possibilita sua comparação com outras ontologias existentes. É útil para se identificar os conceitos consensuais, que refletem as substâncias ou entidades pertencentes ao domínio. As variações indicam distinções em relação a peculiaridades de aplicação.

Uma vez identificados os entes e seus atributos no Espaço de Informação específico, pode-se identificar os Atos de Transformação aplicáveis a eles. Estes atos determinam o uso que a ontologia pode ter e permitem validar a sua adequação segundo o seguinte critério:

Se todos os atos aplicáveis podem ser descritos em termos dos entes mapeados,

então a ontologia é adequada ao propósito pretendido,

senão a ontologia é incompleta ou inadequada.

\subsubsection{Utilizando os princípios tecnológicos}

Para o uso da ontologia, especificamente no nível tecnológico, deve-se adequá-la para que ela responda às questões de competências. Aqui, é possível criar determinadas classes de agregação ou de relação de modo a responder às questões de competência às quais se destina.

Os princípios tecnológicos definidos pelo CPAl oferecem, cada um deles, uma perspectiva para a construção de ontologias de domínio são:

- A distinção dos espaços. Uma ontologia de domínio é um espaço de informação distinguível - uma arquitetura da informação designada ou desenhada (AID), construída sobre um espaço de informação percebido - que, por sua vez, é uma arquitetura da informação percebida (AIP). A própria ontologia é a representação do espaço de informação percebido. Este procedimento é realizado através do ato de transformação Modelar, representado na

Perspectivas em Gestão \& Conhecimento, João Pessoa, v. 7, n. 2, p. 122-159, jul./dez. 2017. 
Figura 16. $\mathrm{O}$ ato de modelar altera a forma, o contexto, o significado - ou todos eles - de uma AIP, gerando uma AID. É fundamental que o espaço de informação a ser modelado seja bem caracterizado. Ele deve ser claramente definido para evitar a extrapolação de escopo durante a construção da ontologia de domínio. Por outro lado, a própria ontologia deverá ser um espaço de informação correspondente àquele que está sendo modelado. Cada elemento significativo no espaço de informação percebido deverá ter um correspondente (unitário ou composto) no espaço de informação desenhado.

Figura 16 - Ato de modelar

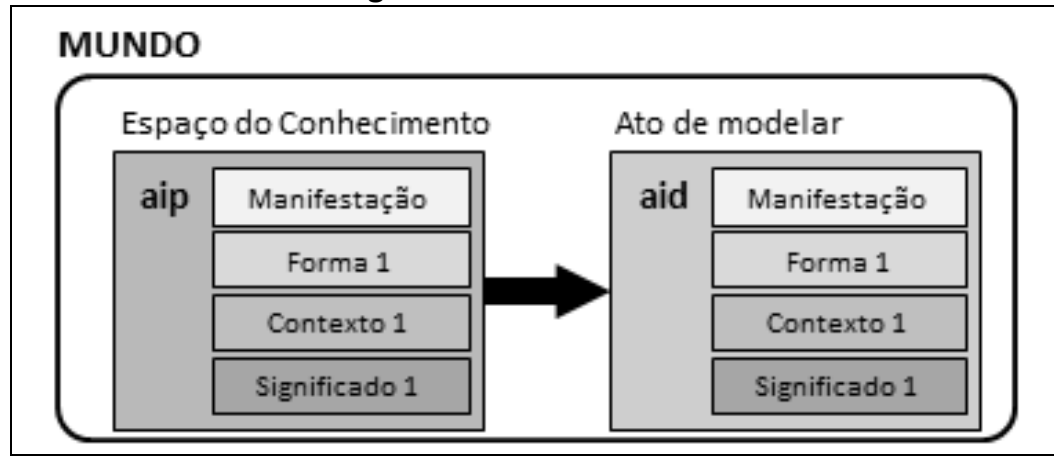

Fonte: Siqueira (2012)

- A criação de artefatos: criar artefatos é utilizar representações como instrumentos de manipulação da realidade do sujeito. No contexto da criação de ontologias de domínio, a própria ontologia é um artefato que pretende representar o mundo, dentro de determinado viés. Ela corresponde a uma AID. Observe-se que, conforme caracterizado por Siqueira (2012), a criação de artefatos em Al trabalha com as categorias de Manifestação, Forma, Contexto e Significado. Mas entre a AIP - o entendimento do espaço de informação a ser modelado - e a AID, a categoria da manifestação não pode ser alterada. Isto significa que não deverá haver um hiato de representação entre o domínio que está sendo estudado e a ontologia que foi criada a partir dele. Este é um critério de validação da ontologia.

- A Simulação: o princípio da Simulação (SIQUEIRA, 2012) possibilita que uma estrutura seja representada por outros elementos que não a constituem originalmente. Uma ontologia de domínio é um instrumento de simulação, devendo suportar a representação estática e dinâmica do espaço de informação que modela.

- A aplicação de atos de transformação: o principal objetivo de uma tecnologia é a interferência na realidade com vistas a transformá-la. A criação de uma ontologia de domínio é um ato de transformação que pretende, primariamente, representar uma realidade tanto para compreendê-la, o que equivale ao esforço de análise, quanto para modificá-la.

A ontologia de domínio deverá suportar a execução de atos de transformação sobre ela. Isto é feito por simulação. Ser capaz de simular uma transformação utilizando a ontologia equivale a ser capaz de executar a transformação no espaço de informação original.

Tome-se, por exemplo, um sistema de software. Todos os componentes de um sistema são entes lógicos representados dentro de uma ontologia de domínio construída em termos computacionais. A possibilidade de aplicar atos de transformação no software - o que equivale a executar operações sobre os entes lógicos representados - possibilita a interpretação de manipulação equivalente na realidade. É desta forma que uma ontologia de domínio possibilita a transformação da realidade que ela modela. 


\subsection{Estudo de caso}

Neste capítulo, aplicam-se as orientações da Al para a construção de ontologias de domínio apresentadas na seção 4.1. O objetivo deste estudo de caso é exemplificar a utilização das orientações decorrentes da Al para a construção de ontologias de domínio.

O domínio escolhido para a criação da ontologia foi o produto GovContaCaixa². O GovContaCaixa é apresentado como uma maneira simples de gerir todas as contas sob a responsabilidade de um determinado tipo de correntista, definido como um gestor público de qualquer área administrativa que possua contrato com a CAIXA. O escopo utilizado na criação de uma ontologia de domínio é exatamente como apresentado na página indicada, isto é: (i) o que é o produto; (ii) a quem se destina; e (iii) como funciona. Nenhuma consulta ou entrevista foi feita, pois se assumiu que todo o conhecimento disponível sobre o assunto está disponível na página Web concernente.

Considera-se aqui a aplicação de cada um dos momentos do MAIA na construção de uma ontologia de domínio para o produto GovContaCaixa. Este caso não é exaustivo e tem por finalidade apenas ilustrar o uso das recomendações apresentadas. Observa-se que a aplicação do MAIA possibilita tanto uma compreensão do domínio da informação quanto a sua modificação para atender aos critérios e finalidades para os quais se destina.

Escutar. Aplicando o procedimento para o momento Escutar ao domínio GovContaCaixa, obteve-se os resultados detalhados a seguir. Os interessados por este domínio são descritos na própria página: (i) governadores (Escutar 1); (ii) prefeitos (Escutar 2) e (iii) funcionários de órgãos públicos em geral (Escutar 3). 0 interesse destes é dispor de uma ferramenta para facilitar a gestão de contas sob sua administração. A função, portanto, do GovContaCaixa é o fator delimitador do interesse. Deve ser possível, com uma ontologia, expressar os atos do correntista relativamente à movimentação de contas vinculadas à sua administração.

Pensar. Aplicando estes procedimentos do momento Pensar ao domínio definido, foram identificados os seguintes conceitos chave: (i) conta vinculada, (ii) administração, (iii) agência, (iv) administração pública, (v) custo de implantação, (vi) usuário, (vii) extrato, (viii) pagamento, (ix) aplicação, $(x)$ segurança, (xi) número da conta, (xii) sistema GovCaixa Eletrônico, (xiii) facilidades, (xiv) gestor principal. Esses conceitos foram identificados a partir da seleção de substantivos no domínio de informação analisado - no caso a página com a descrição do produto. A análise dos conceitos identificados permitiu unir Administração e Administração Pública e tomar o Número de Conta como atributo de conta. Para aplicar os critérios de interesse para a gestão de contas da administração vinculada (critério definido no passo Escutar), os conceitos chave devem ser articulados segundo a sua pertinência ou não ao interesse identificado. No caso em estudo, todos os conceitos pertencem a este domínio. 0 primeiro mapeamento resultou nas classes identificadas, conforme mostrado na Figura 17.

A partir da representação do domínio da informação, passa-se a caracterizar cada um dos elementos aprovados segundo os critérios de seleção definidos, resultando em uma coleção de entes adequadamente identificados com seus atributos e relacionamentos. Organizando as classes dentro de uma hierarquia de relacionamento obtém-se a representação mostrada na Figura 18.

Para obter os elementos como mostrados na figura, utilizaram-se os conceitos de organização de classes em estruturas Todo-Parte (em que os elementos são parte de um todo ou são decomposições dele) e Generalização-Especialização (em que as classes são tomadas

\footnotetext{
${ }^{2}$ Disponível em: http://www.caixa.gov.br/poder-publico/apoio-poder-publico/servicos-caixa/govconta/Paginas/default.aspx.
}

Perspectivas em Gestão \& Conhecimento, João Pessoa, v. 7, n. 2, p. 122-159, jul./dez. 2017. 
como derivadas umas das outras por Especialização - identificação de características específicas - ou Generalização - agrupamento por atributos comuns).

Construir. A representação definida precisa ser capaz de abranger cada uma das operações que podem ser executadas dentro do domínio. Uma investigação sobre as operações definidas no domínio dado por GovContaCaixa indica a necessidade de duas operações: Fazer Pagamentos e Tirar Extratos. A representação apresentada possibilita a realização de cada uma destas operações sobre a ontologia apresentada. Para fazer pagamentos, utiliza-se a Classe conta em conjunto com a classe ContaVinculada e realiza-se uma movimentaçãoNaConta do tipo Pagamento. Data, valor e identificação de operações são atributos da movimentação. Em Tirar Extrato da Conta, utilizam-se a Conta e a lista de movimentaçãoNaConta para compor o próprio extrato e apresentá-lo para o usuário solicitante. A Ontologia proposta permite, então, a execução das operações pretendidas no domínio.

Habitar. Uma vez definidas as bases de utilização da ontologia, passa-se à sua tradução em uma tecnologia adequada. No caso em estudo deveria ser construído um sistema computacional específico utilizando a ontologia mapeada para a realização das operações definidas no escopo do domínio.

Figura 17 - Taxonomia de conceitos

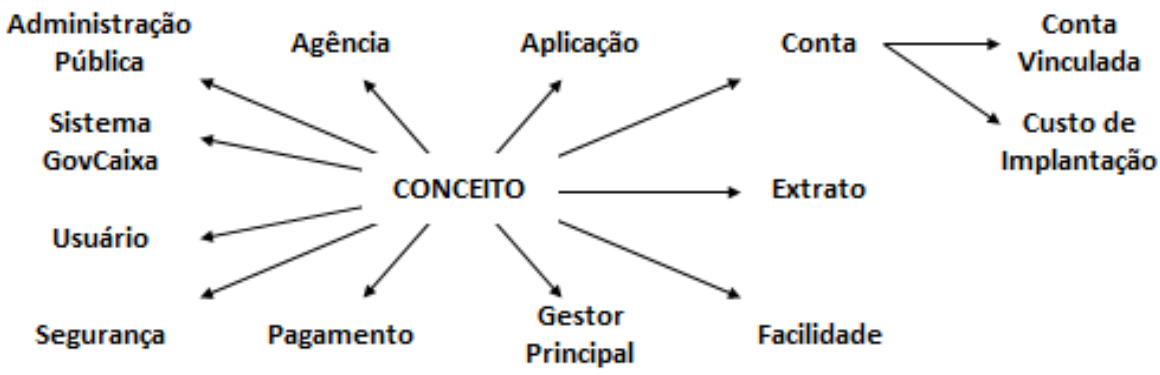

Fonte: os autores

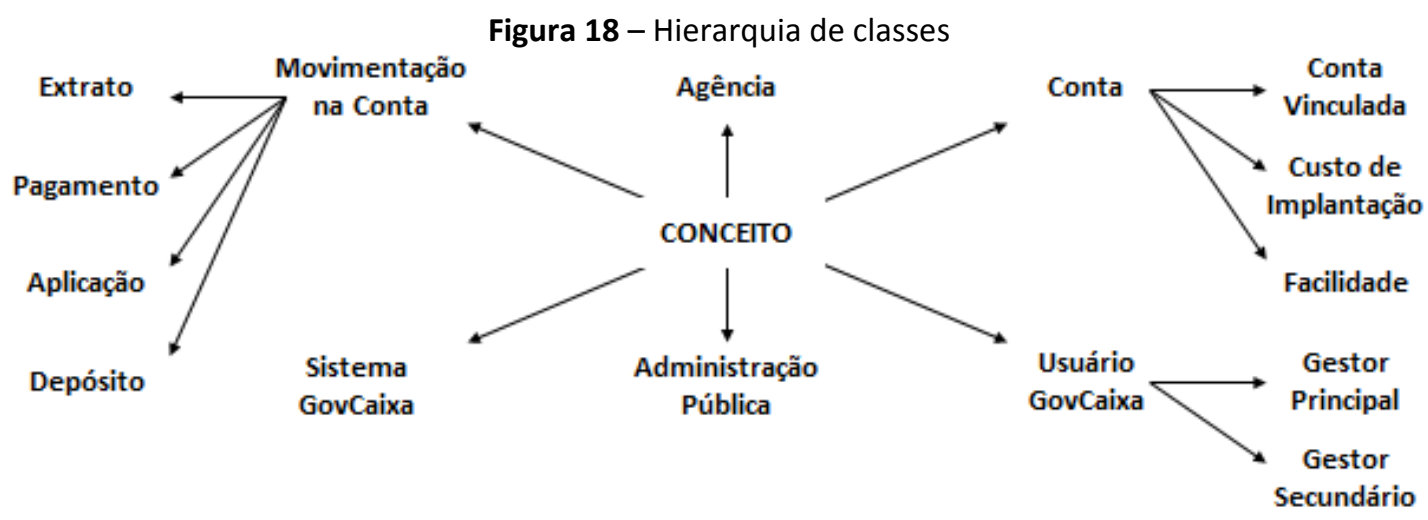

Fonte: os autores

\section{CONSIDERAÇÕES FINAIS}

A pesquisa teve como objetivo geral criar um processo, baseado nas contribuições da Al proposta pelo CPAI, para a construção de ontologias de domínio segundo o ponto de vista formal de um construto científico.

As contribuições da Al foram instrumentalizadas para a criação de um processo que permite a criação de ontologias com um viés segundo o qual algumas vantagens podem ser observadas. Tais vantagens podem ser sintetizadas pelo caráter exaustivo de pontos de 
atenção a serem considerados na constituição de uma ontologia, o que garante uma completude ao artefato no que tange às características desejáveis.

O problema de pesquisa definido neste trabalho teve como motivação a constante dificuldade de utilizar os elementos teóricos tradicionais em relação à modelagem dos problemas da organização. O contato com os temas tratados no CPAI permitiu observar que o uso daqueles conceitos pode facilitar a compreensão dos elementos relativos à informação organizacional. Daí a ideia de se aplicar os constructos do CPAI no ambiente de trabalho. 0 resultado mostrou-se promissor e disto resultou o intento de dissertar sobre o tema neste mestrado profissional.

O principal resultado desta pesquisa foi o mapeamento das contribuições do CPAl em recomendações de uso para a construção de ontologias de domínio. A identificação da ontologia como expressão de uma arquitetura da informação e o aproveitamento de seu referencial teórico como disciplina permite destacar a consistência de uma abordagem teórica baseada em Al.

A partir desta pesquisa puderam-se identificar alguns trabalhos futuros: (i) estudos de casos de aplicação das recomendações produzidas na construção de ontologias de domínio específicas; (ii) um aprofundamento da aplicação do MAIA na construção de ontologias de domínio específicas; (iii) a caracterização dos artefatos intermediários que podem ser produzidos e os processos que devem ser seguidos para a construção de ontologias de domínio dentro das recomendações efetuadas; (iv) a validação dos fatores críticos de sucesso identificados em um conjunto significativo de amostras experimentais.

A pesquisa naturalmente apresenta um conjunto de limitadores. Sabe-se que a análise das contribuições do CPAI foi mais abrangente do que profunda. Outros trabalhos poderiam aprofundar tais contribuições em outras áreas de conhecimento. Não se fez uma apreciação crítica das contribuições teóricas, antes se buscou a aplicabilidade delas. Outros trabalhos poderiam empreender uma avaliação crítica do corpus teórico produzido pelo Grupo de Brasília de modo a validar o conjunto da produção.

\section{REFERÊNCIAS}

ALBANI, A.; DIETZ, J. L. G. Enterprise ontology based development of information systems. International Journal of Internet and Enterprise Management, v. 7, n. 1, p. 41-63. 2011.

ALBUQUeRQUE, A. R. R. Discurso sobre fundamentos de Arquitetura da Informação. Tese (Doutorado em Ciência da Informação e Documentação) - Universidade de Brasília, 2010.

ARAÚJO, L. C. Configuração: uma perspectiva de Arquitetura da Informação da Escola de Brasília. Dissertação (Mestrado em Ciência da Informação) - Universidade de Brasília, 2012.

BAYLE, S. Information architecture: a brief introduction. 2003. Online. Disponível em: http://iainstitute.org/tools/download/Bailey-IAlntro.pdf. Acesso em: 07 nov 2014.

BETZ, F; PHILLIPS, F. Model ontology and information architecture. In: PORTLAND INTERNATIONAL CONFERENCE ON MANAGEMENT OF ENGINEERING AND TECHNOLOGY (PICMET), 2001, Portland. Proceedings... Portland (EUA), 2015. p. 367-373.

BUNGE, M. La investigación Científica: Su estrategia y su filosofia. Barcelona (Espanha): Ariel, 1980.

CASTELLS, M. A sociedade em rede: a era da informação: economia, sociedade e cultura. São 
Paulo: Paz e Terra, 1999.

CAVALCANTE, G. V. Ciência das Redes: aspectos epistemológicos. Tese (Doutorado em Ciência da Informação) - Universidade de Brasília, 2009.

CIANCONI, R. Gestão do Conhecimento: visão de indivíduos e organizações no Brasil. Tese (Doutorado em Ciência da Informação) - IBICT/Universidade do Rio de Janeiro, 2003.

COSTA, I. M. Um Método para Arquitetura da Informação: Fenomenologia como base para o desenvolvimento de arquiteturas da Informação aplicadas. Dissertação (Mestrado em Ciência da Informação) - Universidade de Brasília 2009.

COHN, A. G. Qualitative spatial representation and reasoning techniques. In: BREWKA, G. HABEL, C.; NEBEL, B. (Eds). Proceedings of KI-97, Lecture Notes on Artificial Intelligence, v. 1303, p. 1-30, Springer-Verlag, 1997.

DADE-ROBERTSON, M. The Architecture of Information: architecture, interaction design and the patterning of digital information. New York (EUA): Routledge, 2011.

DAVENPORT, T. H. Ecologia da Informação. São Paulo: Ed. Futura, 1998.

DIETZ, J. L. Enterprise Ontology: Theory and Methodology. Berlim (Alemanha): SpringerVerlag, 2006.

DILLON, A. Information Architecture in JASIST Just Where Did We Come From? Journal of the American Society for Information Science and Technology, v. 10, n. 53, p. 821-823, 2002.

DRUCKER, P. Sociedade Pós-Capitalista. 2. ed. São Paulo: Pioneira/Novos Umbrais, 1993.

DUARTE, J. C. Uma arquitetura ágil da informação organizacional. Tese (Doutorado em Ciência da Informação) - Universidade de Brasília, 2010.

ECHEVERRÍA, R. Ontologia del Lenguaje. 4. ed. Santiago (Chile): Dolmen Ediciones, 1997.

GIGCH, J. P.; PIPINO, L. L. In search of a paradigm for the discipline of information systems. Future Computing Systems, v. 1, n. 1, p. 71-97, 1986.

GIL, A. C. Como elaborar projetos de pesquisa. 4. ed. São Paulo: Editora Atlas, 2002.

GRUBER, T. R. Toward principles for the design of ontologies used for knowledge sharing. International Journal Human-Computer Studies, v. 43, n. 5-6, p. 907-928, 1995.

GUIZZARDI, G. On ontology, ontologies, conceptualizations, modeling languages, and (meta) models. In: CONFERENCE ON DATABASES AND INFORMATION SYSTEMS IV: SELECTED PAPERS FROM THE SEVENTH INTERNATIONAL BALTIC CONFERENCE DB\&IS'2006, 2006, Vilnius (Lituânia). Proceedings... Amsterdã (Holanda): IOS Press, 2007. p. 18-39.

HAGEDORN, K. The Information Architecture Glossary. 2000. Online. Disponível em: http://argus-acia.com/white papers/iaglossary.html. Acesso em: 11 out 2016.

Perspectivas em Gestão \& Conhecimento, João Pessoa, v. 7, n. 2, p. 122-159, jul./dez. 2017. 
HARRIS, K. et al. The Impact of knowledge management on enterprise architecture. Stanford (EUA): Gartner Group, 1999.

HAVERTY, M. Information architecture without internal theory: An inductive design process. Journal of the American Society for Information Science and Technology, v. 10, n. 53, p. 839845, 2002.

INFORMATION ARCHITECTURE INSTITUTE. What is Information Architecture. 2008. Online. Disponível em: http://iainstitute.org/documents/learn/What is IA.pdf. Acesso em: 30 out 2016.

ISBANDI; ALBARDA. Design of information architecture with Enterprise Ontology approach: A case study in West Java Educational Quality Assurance Institution. In: INTERNATIONAL CONFERENCE ON ICT FOR SMART SOCIETY (ICISS), 2013, Jakarta (Indonésia). Proceedings... 2013. p. 1-6.

KUHN, T. S. The Structure of Scientific Revolutions. The kindle eletronic editon. Chicago (EUA): The University Chicago Press, 2003.

LACERDA, F. Arquitetura da Informação: aspectos epistemológicos, científicos e práticos. Dissertação (Mestrado em Ciência da Informação) - Universidade de Brasília, 2005.

LAMB, A. Information architecture for the web: web development for schools and libraries. 2004. Online. Disponível em: http://eduscapes.com/arch/ia/overview1.htm. Acesso em: 31 ago 2016.

LIMA-MARQUES, M. De la connaissance à la paraconsistance: un modèle d'apresentacion pour la résolution des conflits aériens. Tese (Doutorado em Ciência da Computação) Université Paul Sabatier, França, 1992.

LIMA-MARQUES, M. Ontologias: da filosofia à representação do conhecimento. Brasília: Thesaurus Editora, 2006.

LIMA-MARQUES, M. Outline of a theoretical framework of Architecture of Information: a School of Brasília proposal. In: Logic without frontiers: Festschrift for Walter Alexandre Carnielli on the occasion of his 60th birthday, v. 17. London: College Publications, 2011.

LOGAN, D. Knowledge Management Is Critical to Organizing and Accessing a Company's Intellectual Assets. Gartner Report. Stanford (EUA): Gartner Goup, Inc., 2006.

LORENS, E. M. Aspectos normativos da segurança da informação: um modelo de cadeia de regulamentação. Dissertação (Mestrado em Ciência da Informação) - Universidade de Brasília, 2007.

MACEDO, F. L. O. Arquitetura da Informação: aspectos epistemológicos, científicos e práticos. Dissertação (Mestrado em Ciência da Informação) - Universidade de Brasília, 2005.

MASI, D. de. Criatividade e Grupos Criativos, v. 1: Descoberta e Invenção. Rio de Janeiro: Sextante, 2003.

Perspectivas em Gestão \& Conhecimento, João Pessoa, v. 7, n. 2, p. 122-159, jul./dez. 2017. 
MARCIANO, J. L. P. Segurança da Informação: uma abordagem social. Tese (Doutorado em Ciência da Informação) - Universidade de Brasília, 2006.

MELO, A. M. C. Um modelo de Arquitetura da Informação para processos de investigação científica. Dissertação (Mestrado em Ciência da Informação) - Universidade de Brasília, 2010.

MORIN, E. O Método. O conhecimento do conhecimento. 2a ed. Lisboa (Portugal): EuropaAmérica, 1999.

NASCIMENTO, M. S. O. Proteção ao Conhecimento: uma proposta de fundamentação teórica. Dissertação (Mestrado em Ciência da Informação) - Universidade de Brasília, 2008.

NONAKA, I.; TAKEUCHI, H. The knowledge-creating company: How Japanese companies create the dynamics of innovation. New York (EUA): Oxford University Press, 1995.

OLIVEIRA, C. B. Uma proposta de Arquitetura da Informação para o processo de inovação em centros de pesquisa. Tese (Doutorado em Ciência da Informação) - Universidade de Brasília, 2012.

OLIVEIRA, E. C. Autoria de documentos para a Web Semântica: um ambiente de produção de conhecimento baseado em ontologias. Tese (Doutorado em Ciência da Informação) Universidade de Brasília, 2006.

POLANYI, M. Personal Knowledge: Towards a post-critical Philosophy. Chicago (EUA): University of Chicago Press, 1974.

PORTER, M. E. What's strategy? Harvard Business Review, v. 74, n. 6, 1996.

REIS, G. A. dos. Centrando a Arquitetura da Informação no usuário. Dissertação (Mestrado em Ciência da Informação) - Escola de Comunicação e Artes. Universidade de São Paulo, 2007.

ROSENFELD, L.; MORVILLE, P. Information Architecture for the World Wide Web. Sebastopol (EUA): O'Reilly Media, Inc., 2002.

ROSS, J. W.; WEILL, P.; ROBERTSON, D. Enterprise Architecture as Strategy: Creating a foundation for business execution. Boston (EUA): Harvard Business School Press, 2006.

SANTOS, D. P. L. dos. Um arcabouço teórico para a autoria de documentos visando atenuar o surgimento de ambiguidades. Dissertação (Mestrado em Ciência da Informação) Universidade de Brasília, 2006.

SILVA, L. B. Ambiguidades da língua portuguesa: recorte classificatório para a elaboração de um modelo ontológico. Dissertação (Mestrado em Ciência da Informação) - Universidade de Brasília, 2006.

SIQUEIRA, A. H. de. A Lógica e a Linguagem como fundamentos da Arquitetura da Informação. Dissertação (Mestrado em Ciência da Informação) - Universidade de Brasília, 2008.

SIQUEIRA, A. H. de. Arquitetura da Informação: uma proposta para a fundamentação e 
caracterização de uma disciplina científica. Tese (Doutorado em Ciência da Informação) Universidade de Brasília, 2012.

SIQUEIRA, A. H. de. Aprendizado Corporativo: necessidade da arquitetura da informação organizacional, 2014. (Texto não publicado)

SOWA, J. F. Knowledge Representation: Logical, Philosophical, and Computational Foundations. $3^{\text {a }}$ ed. Pacific Brove (EUA): Brooks Cole Co. 2000.

SPEK, R. van der; SPIJKERVET, A. Knowledge management: handling knowledge with intelligence. Handboek Effectief Opleiden, v. 9, n. 13, p. 1-32, 1995.

STEWART, T. A. A Riqueza do Conhecimento. O capital intelectual e a Organização do século XXI. São Paulo: Ed. Campus, 2001.

SUGANUMA, S. Qualidade da Informação: uma construção metodológica de definição do conceito. Dissertação (Mestrado em Ciência da Informação) - Universidade de Brasília, 2006.

TALMY, L. How languages structure space. In: PICK, H.; ACREDOLO, L. (Eds) Spatial Orientation: Theory, Research, and Application, New York (EUA): Plenum Press, p. 225-282, 1983.

TALMY, L. The Windowing of attention in language. In: SHIBATANI, M.; THOMPSON, S. (Eds) Grammatical Constructions: Their Forms and Meaning, Oxford (Inglaterra): Oxford University Press, pp. 235-287, 1996.

WIERZBICKA, A. Semantics: Primes and Universals, Oxford (Inglaterra): Oxford University Press, Oxford, 1996.

WURMAN, R. S. Information Architects. 2. ed. Lakewood (EUA): Watson-Guptill Pubications, 1997.

ZACHMAN, J. A framework for information systems architecture. IBM Systems Journal, v. 26, n. 3, p. 276-292, 1987.

ZELENY, M. Management support systems: Towards integrated knowledge management. Management, v. 7, n. 1, p. 59-70, 1980. 